\title{
Landslide hazard and land management in high-density urban areas of Campania region, Italy
}

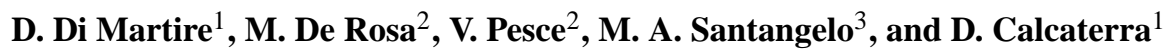 \\ ${ }^{1}$ Department of Hydraulic, Geotechnical and Environmental Engineering, Federico II University of Naples, Italy \\ ${ }^{2}$ Architecture studio, Battipaglia (province of Salerno), Italy \\ ${ }^{3}$ Basin Authority of Northwestern Campania Region, Naples, Italy
}

Correspondence to: D. Calcaterra (domenico.calcaterra@unina.it)

Received: 5 September 2011 - Revised: 29 December 2011 - Accepted: 5 January 2012 - Published: 12 April 2012

\begin{abstract}
Results deriving from a research focused on the interplay between landslides and urban development are presented here, with reference to two densely populated settings located in the Campania region, Italy: the city of Naples and the island of Ischia. Both areas suffer adverse consequences from various types of landslides since at least $2000 \mathrm{yr}$. Our study evidences that, despite the long history of slope instabilities, the urban evolution, often illegal, disregarded the high landslide propensity of the hillsides; thus, unsafe lands have been occupied, even in recent years, when proper and strict rules have been enacted to downgrade the landslide risk. It is finally argued that future guidelines should not be entirely based upon physical countermeasures against mass movements. On the contrary, national and local authorities should enforce the territorial control, obliging citizens to respect the existing regulations and emphasizing the role of alternative, non-structural solutions.
\end{abstract}

\section{Introduction}

Anthropogenic modifications to the natural environment are, along with climatic and seismic events, the main factors which can trigger landslides. This makes urban environments particularly vulnerable, especially where demographic pressure rapidly grows over time, thus, inducing a parallel increase in land use demand. The growth of urban populations, common in both developed and developing countries, is responsible for an inevitable expansion of urban centres and, above all, of peri-urban areas; the latter progressively move towards marginal lands such as flood-prone areas and hillslopes, otherwise unsuitable for development.
Such critical conditions are further aggravated when the urbanisation of unfavourable land takes place without respecting the rules and regulations; to this regard, known cases worldwide come from several countries, where slums and squatter settlements have occupied unsafe hillslopes (e.g., the Brazilian "favelas"). The first report on slums was carried out by the United Nations in 2003. Based on 2001 data, the report stated that, at that time, 924 million people, or $31.6 \%$ of the world's urban population, lived in slums (UnHabitat, 2003). Even if the majority of them were in the developing regions, accounting for $43 \%$ of the urban population, Europe and other developed countries had 54 million slum dwellers (about $6 \%$ of the world's total). Some cities of these latter countries, such as Los Angeles, Moscow and Naples, show different types of slum housing, which depend upon the construction type, location, legality status, etc.

In the case of Naples, Italy, the concept of the "unauthorized city" has been introduced (Scaramella, 2003): this city is made up of areas of illicit construction on former agricultural lands. Here, no building permits are issued, the zoning plan is systematically violated and an illegal, but not informal, urban expansion is realised. Such a phenomenon started soon after World War II and became more evident from the 1970s onward.

As a consequence, huge boroughs grew in a few decades, rapidly reaching quite a high population density, in the order of 6000/7000 inhabitants per square kilometre, and partly occupying areas exposed to natural hazards such as floods and landslides (Fig. 1).

A similar trend has characterised the urban development of several minor towns in the province of Naples, such as the six municipalities of the Ischia Island, where the tourism industry gave a strong impulse to the realisation of a number of illegal second houses. 


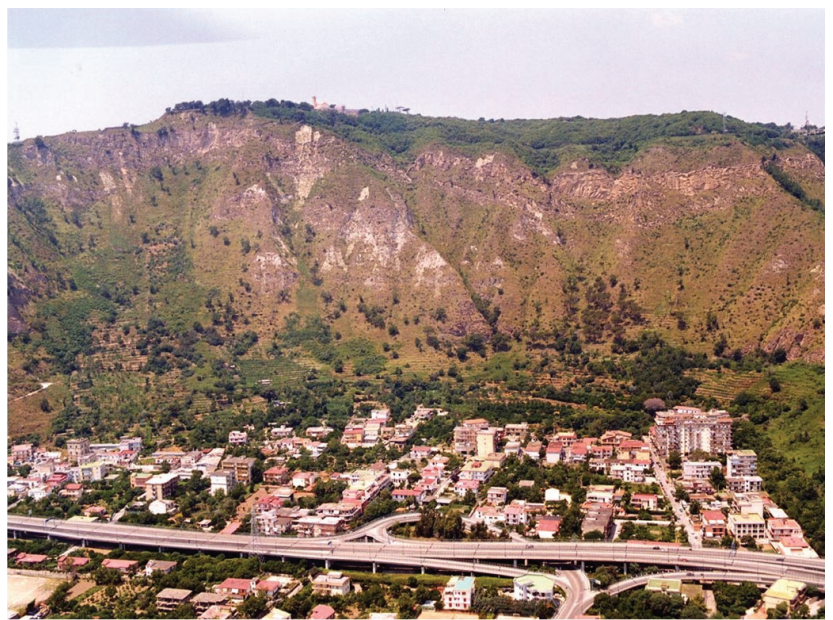

Fig. 1. The borough of Soccavo and the southern slope of the Camaldoli hill, Naples, Italy.

The Phlegrean Fields include both a continental district, where Naples and some minor municipalities are present, and the Phlegrean islands of Ischia and Procida. This district, which hosts Naples, the region capital and third city in Italy in population (around one million inhabitants), is an emblematic urban setting highly vulnerable to a variety of natural geohazards, such as volcanic eruptions, bradyseism, earthquakes, coastal erosion, sinkholes and mass movements. With regards to Naples, which extends over an area of around $117 \mathrm{~km}^{2}, 27 \%$ of its territory has been recently classified into the four classes of landslide risk (BANCR, 2002, 2010).

In the following, the main features of historical and recent landslides that occurred in Naples and Ischia island will be described, along with an outline of the relevant stages which have characterised the urban growth of these territories. These aspects will be jointly examined, focusing on some selected areas: the aim is to show how risk has increased over time, as a direct consequence of ill-suited urban policies. In conclusion, some considerations will be spent on remedial measures and best practices that hopefully public administrators should adopt to ensure a safer territory to their own citizens.

\section{Geological setting}

The town of Naples and the island of Ischia fall within the Phlegraean volcanic district (a.k.a. Phlegraean Fields Fig. 2). The largest and most important feature of the continental sector of the Phlegraean Fields is represented by the Phlegraean Caldera, interpreted by Orsi et al. $(1992,1996)$ as a nested, resurgent caldera, deriving from two main collapses, related to the Ignimbrite Campana (Campanian Ignimbrite, IC - volume erupted: $80-500 \mathrm{~km}^{3}$; age: $\left.39 \mathrm{ka}\right)$ and to the Tufo Giallo Napoletano (Neapolitan Yellow Tuff,

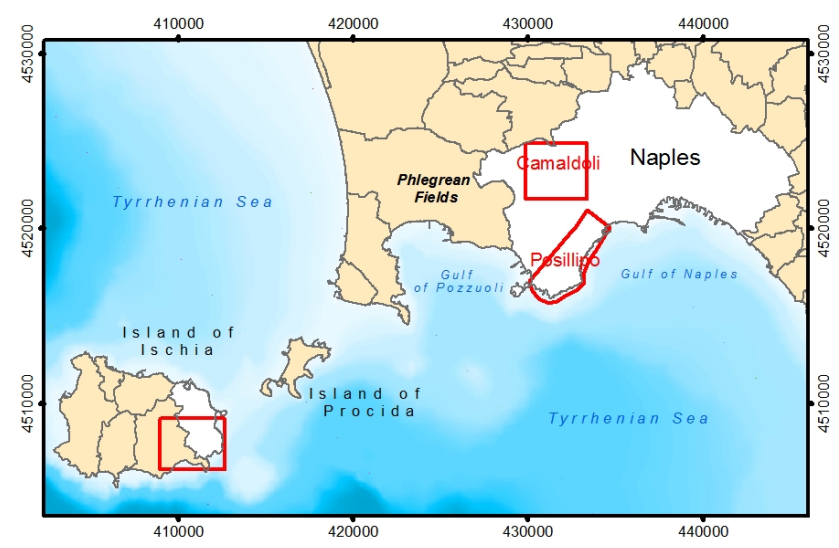

Fig. 2. Location map of the studied areas in the bay of Naples.

TGN - volume erupted: $40-50 \mathrm{~km}^{3}$; age: $15 \mathrm{ka}$ ) eruptions, respectively. The most notable feature of the island of Ischia is Mount Epomeo, interpreted as a resurgent block within a pre-existing caldera (Orsi et al., 1991). Eruptions that occurred in historical times (Ischia island: Arso, $1302 \mathrm{AD}$; Phlegrean Fields: Monte Nuovo, 1538 AD), bradyseismical crises (1969-1972, 1982-1984) and widespread fumarole and thermal spring activity testify that the whole area is an active volcanic field.

In Naples, the oldest deposits crop out along the slopes of the Camaldoli hill (Tufi di Torre Franco - 42 ka, Alessio et al., 1973 - Piperno and Breccia Museo). However, the main tuff formation within the urban area is the TGN, well exposed along the slopes of the urban hills (Camaldoli, Posillipo, S. Martino, Poggioreale), reaching a thickness of several tens of metres up to about $100 \mathrm{~m}$. The TGN consists of two members: member A, a succession of cineritic and pumiceous lapilli layers, and member B, a deposit made of cineritic layers with dispersed rounded pumices (Morra et al., 2010). The volcaniclastic sequence is closed by loose, unconsolidated pyroclastic deposits referable to 75 volcanic units (Di Vito et al., 1999): their ages range between $15 \mathrm{ka}$ and the 1538 AD eruption of Mt. Nuovo. These deposits are made up of a repeated alternance of pumice, ashes, scoriae and paleosoils, usually stratified, with a thickness ranging from a few to some tens of metres. In the urban coastal plains (Fuorigrotta, Chiaia), recent and actual marine to continental sediments are also present, usually covered by landfills.

At Ischia, lavas, tuffs and pyroclastic deposits ranging in age between ca. $150 \mathrm{ka}$ and $1302 \mathrm{AD}$ (Arso eruption) crop out (Rittmann and Gottini, 1980; Vezzoli, 1988). Within the Ischia paleo-caldera $(\sim 55 \mathrm{ka})$ marine sediments such as silts, marls and sandstones can be found (Barra et al., 1992). Moreover, in the middle-western part of the island widespread debris deposits crop out, interpreted as the result of ancient mass movements related to the volcano-tectonic uplift of Mt. Epomeo (Vezzoli, 1988; Mele and Del Prete, 1998). 
The landscape of the whole Phlegrean district, including the islands of Ischia and Procida, shows clear evidence of past volcano-tectonic events. Minor hills are, in fact, remnants of older volcanic edifices, while the major slopes of Naples (Camaldoli, Posillipo, Poggioreale hills) derive from the inner walls of the Phlegrean caldera. Moreover, the Phlegrean hills display a significant "relief energy". In fact, notwithstanding their relatively low altitude (max. elevation - Naples: Camaldoli hill, $458 \mathrm{~m}$ a.s.l.; Ischia island: Mt. Epomeo, $790 \mathrm{~m}$ a.s.1.), local hills are characterised by high slope angles $\left(>30^{\circ}\right)$, which reach the highest values where cliff-forming tuffs and lavas crop out. Also the drainage network presents a pronounced structural control, where low-order straight channels clearly prevail, usually coinciding with morphostructural lineaments.

\section{Urban setting}

In the Phlegrean Fields, human presence is recorded since prehistoric times as shown by some stone tools (dated to ca. $5.5 \mathrm{ka}$ ) found at Ischia and by some tombs of Eneolitic Age (about $4.5 \mathrm{ka}$ ) discovered at Naples. However, the first colonies established by Greek refugees date to 8th-7th century BC both in Naples (Parthenope) and on the island of Ischia (Pithekoussai).

Following a number of dominations (Goths, Byzantines, Longobards, Normans, Swabians), Naples, which already in the 8th century was populated by about 35000 people, underwent a substantial transformation in the Angevin era. In fact, having assumed the role of capital city (1266 AD), it recorded a rapid increase in population, along with the nearby coastal belt; the latter began to be developed as a result of settlements mainly due to the swampy nature of the low-lying inland areas of the Campania region.

The reclamation process of the inland areas has been gradual and slow, and still in 18th century the city of Naples was surrounded by marshy and malaric areas. Since the Longobard and Norman ages (6th-7th century onward) many small residential areas (locally known as "casali") were established, with predominantly agricultural features, distributed around the main urban centres. In the outskirts of Naples, some tens of "casali" were developed over the centuries, which produced everything the capital city needed. At the same time, within the urban precincts, scattered settlements grew up, mainly represented by villas located in the coastal areas and hills, and used by nobles for recreational purposes (Di Lorenzo, 2006).

Among the urban boroughs more frequently involved in landslides (see below), Soccavo and Pianura, located at the foot of the Camaldoli hill, derive from two of the original "casali". The first time the name Pianura appears in an official document dates back to the $786 \mathrm{AD}$, while Soccavo is mentioned since 1030 at least.

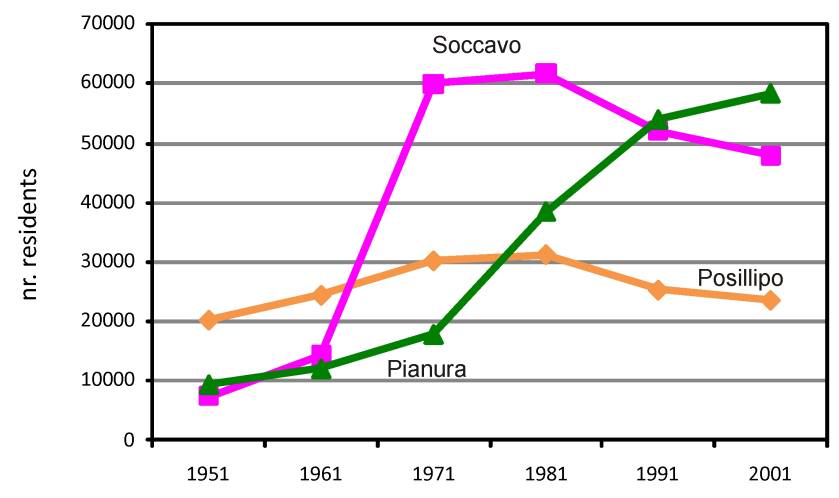

Fig. 3. 1951-2001 trend of residents in the boroughs of Posillipo, Soccavo and Pianura (data from MGCN, 2007).

Soccavo and Pianura remained distinct municipalities after the Italian unification (1860) and until 1926, when both became urban boroughs of the city of Naples. At that time and until the 1950s these areas were scarcely inhabited. At Pianura, only 2270 inhabitants were registered in 1927, a population which rose to about 10000 in 1956 up to about 60000 in 2001, as resulted from the municipal census (MGCN, 2007). At Soccavo, from 1961 to 1971 the population increased from 14343 to 60028 units. Nowadays, more than 105000 live in both boroughs, with a peak density at Soccavo, with more than 9300 inhabitants $\mathrm{km}^{-2}$ (MGCN, 2007). The local demographic growth was associated with a strong demand for new houses, which have been prevailingly built holding the existing rules in contempt.

Posillipo (in Greek, Pausilypum, i.e., pause from pain), occupying the homonymous hill, has been from 1st century BC onward the most sought-after area in the town, enjoying a spectacular view of the Gulf of Naples, with Mt. Vesuvius in the background. From the Byzantine period (7th century) until 16th century at least, some "casali" were established also on the hill of Posillipo (De Seta, 1984), maintaining their condition of isolated settlements for a very long time. In fact, the first urban road connecting the hill with the rest of the city was realised in 1643 only, under the Spanish viceroyalty. Although an urban expansion of the Posillipo settlements had been planned in the last decades of the 19th century, it was only in the 1920s that it really started, favoured by the opening of two other important roads (Manzoni street and Petrarca street). After World War II, also the Posillipo hill underwent an uncontrolled urbanisation, irrespective of plans or building schemes. As a consequence, the population at Posillipo increased about 50\% from 1951 to 1971 (20362 to 30275 ), while nowadays less than 24000 people live on the hill, having followed the same diminishing trend of many other urban boroughs (Fig. 3).

Six municipalities are present on the Ischia island (Barano, Casamicciola Terme, Forio, Ischia, Lacco Ameno, Serrara Fontana), whose urban setting has been repeatedly altered by natural events, such as eruptions, earthquakes, landslides. 
Until World War II, agriculture and fishery were the main activities on the island, rapidly substituted by the tourism industry, the latter initially related to the numerous thermal springs. Tourism brought, along with conspicuous income for the local population, also an uncontrolled diffusion of second houses, mainly illegally built, which from the historical settlements moved up to the hillsides.

The influence of the tourism industry on the urbanisation at Ischia is well demonstrated comparing the trend of residents and buildings in the last decades. From 1961 to 2001, in fact, in all the six municipalities the number of citizens living permanently has increased, from $32 \%$ (Serrara Fontana) to $102 \%$ (Forio) (MGCN, 2007). In the same period, the number of houses had increased exponentially, from a minimum of $+400 \%$ at Casamicciola Terme up to $+2309 \%$ at Forio (Monti, 2006). These figures are complemented by the opposite trend shown by the number of people living in agriculture, which, after a first, sharp reduction in the 1951-1961 interval (e.g.: Serrara Fontana: from $76.5 \%$ to $33 \%$ ) further diminished from 1961 to 2001 all over the island, reaching values between $3.8 \%$ (Lacco Ameno) and $1.9 \%$ (Casamicciola) (MGCN, 2007).

\section{Landslides}

In the Phlegrean district, landslides contribute to landscape evolution since distant historical times.

In fact, at Naples, the oldest known evidence related to a mass movement dates back to the Imperial Roman period (Morra et al., 2010). It is located within the ancient centre of Naples, in the archaeological site under the San Lorenzo church. Here, $7 \mathrm{~m}$ below the present-day ground surface, the city market built in the 1 st century BC is partly buried under a chaotic deposit ascribed to a flood that occurred at the end of the 5th century (TCI, 2001), which probably moved down the slopes of the Caponapoli hill, the northernmost edge of the first Greek-Roman town.

As regards to the island of Ischia, a huge deep-seated gravitational slope deformation, mentioned by Pliny the Elder and Strabo, probably occurred in the 4th century BC, involving an area of about $5 \mathrm{~km}^{2}$ (Del Prete and Mele, 2006).

Despite such striking evidence, slope instabilities in Naples and, more generally, in the Phlegrean region, have been systematically studied in relatively recent years only. It was, in fact, only after an important rainfall-induced event which occurred in February 1986 that researchers paid the due attention to this issue (Beneduce et al., 1988).

In the following years, a number of papers have dealt with the landslides in Naples and the surrounding areas, treating both historical (Calcaterra et al., 2002, 2003b; Calcaterra and de Luca Tupputi Schinosa, 2006) and recent events (Pellegrino, 1994; Calcaterra and Guarino, 1999a, 1999b; Calcaterra et al., 2004a, 2004b, 2005, 2007a, 2007b, 2010a; de

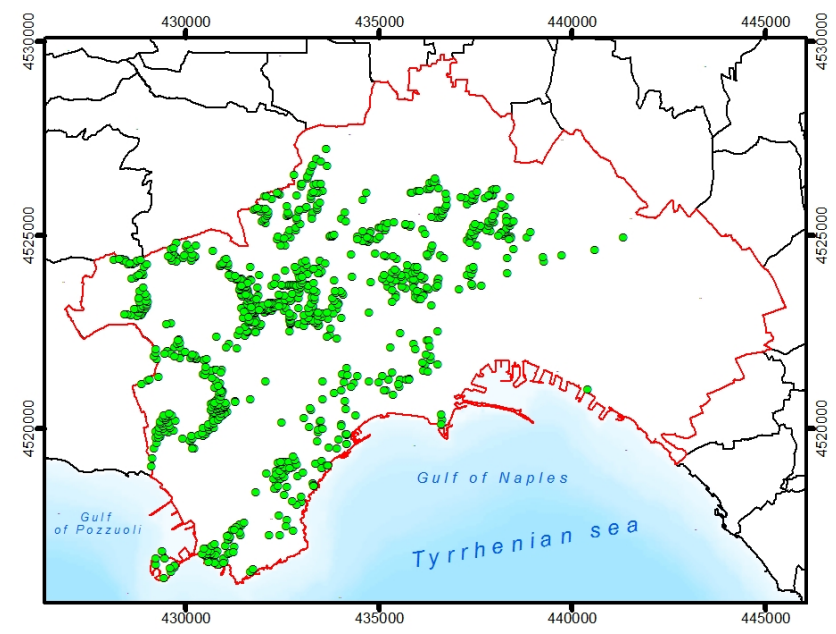

Fig. 4. Landslide-inventory map of the city of Naples.

Riso et al., 2004, 2007; Parise et al., 2004; Palma et al., 2009; Calcaterra, 2010).

In the same years, due attention has been paid to the mass movements in the Ischia island as well (Arrigoni et al., 1995; Guadagno and Mele, 1995; Mele and Del Prete, 1998; Del Prete and Mele, 1999, 2006; Calcaterra et al., 2003b, 2010b; de Riso et al., 2004, Ascione et al., 2007; De Vita et al., 2007; Iovino and Perriello Zampelli, 2007; Palma et al., 2009).

In the next paragraphs, data coming from literature and from new, ongoing studies will be commented, highlighting the main aspects of the Naples and Ischia landslides, respectively.

\subsection{Landslides at Naples}

The current knowledge of landslides in Naples covers a time period from 1868 to 2011, and is based upon field surveys and aerial photo-interpretation, along with a thorough local and national archival research of relevant sources. Accordingly, 1099 individual landslides have been inventoried (Fig. 4) and stored into a geo-database, classifying them as either "historical" or "recent" events, conventionally using the February 1986 event as a temporal divide.

The temporal distribution of the landslides is shown in Fig. 5, where it is evident that the main peak corresponds to the year 1997, while, going back in time, the cited 1986 event represents the most important one. In both cases, landslides were triggered by low-intensity, long-duration rainfalls (Fig. 6).

Most of the landslides that occurred from 1986 onward have been triggered by rainfall events, even though characterised by highly variable values of duration and/or intensity (e.g.: September $2001-183.4 \mathrm{~mm}$ in $4 \mathrm{~h}$; March 2005 $130.2 \mathrm{~mm}$ in $27 \mathrm{~h}$ ); in Fig. 6 some of the Phlegrean events are compared to other landslide-producing storms that occurred in the last decades in the Campania region. 


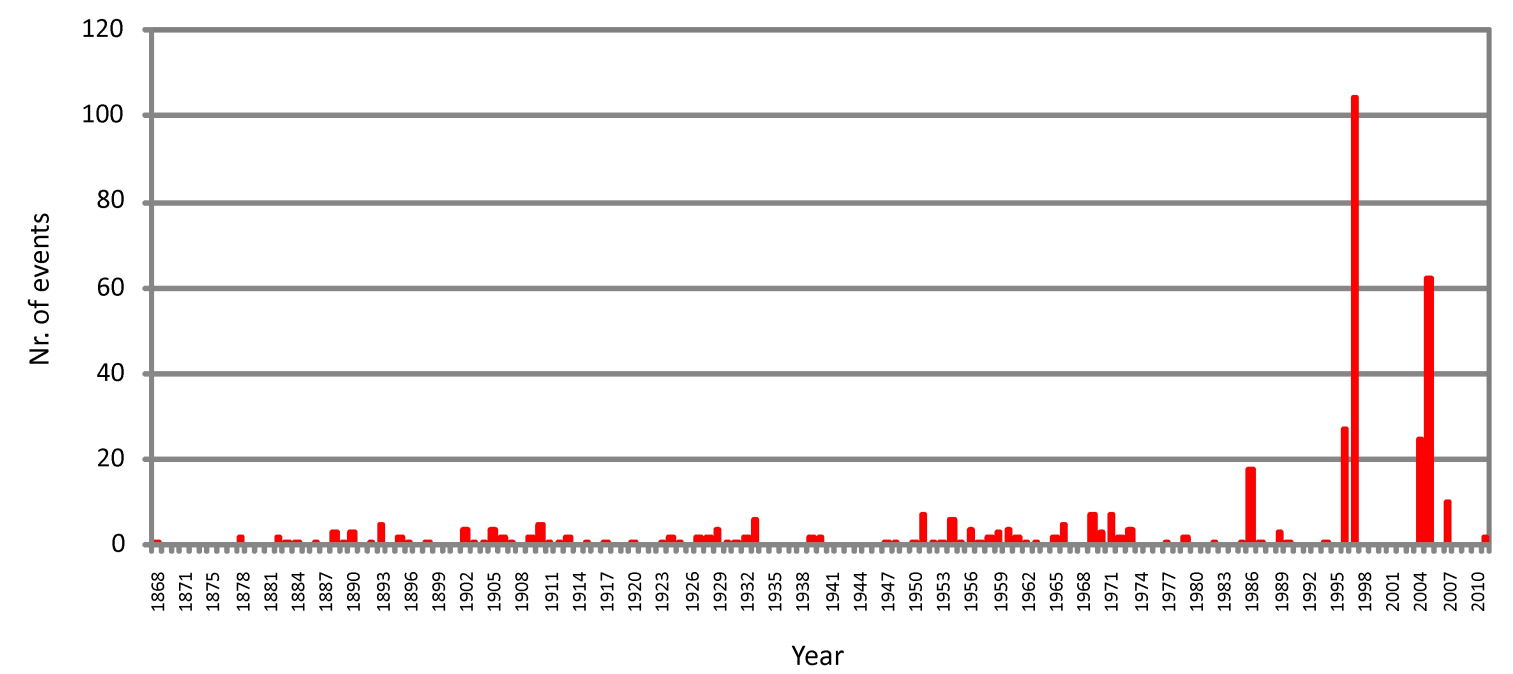

Fig. 5. Annual distribution of the Naples' landslides for the period 1868-2011.

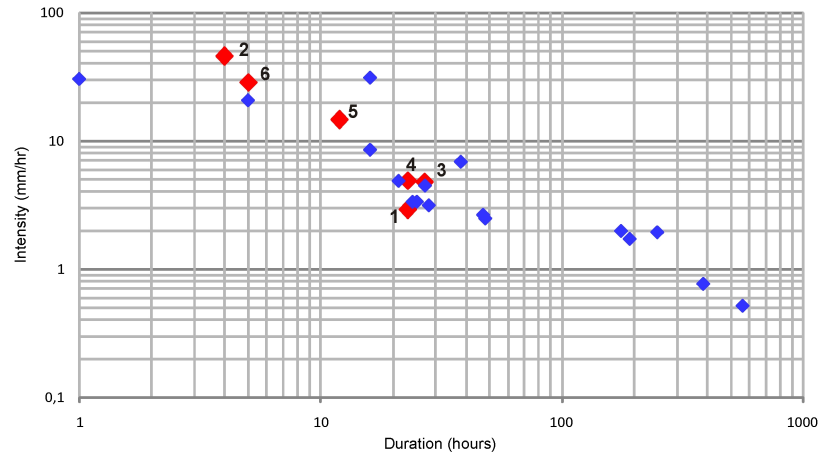

Fig. 6. Duration vs. intensity plot for landslide-producing storms that occurred in the Campania region (after Calcaterra et al., 2000, modified). 1 - Naples, January 1997; 2 - Naples, September 2001; 3 - Naples-Pozzuoli, March 2005; 4 - Ischia, April 2006; 5 - Ischia, November 2009; 6 - Ischia, June 2011.

However, in the last $25 \mathrm{yr}$ anthropogenic actions contributed to alter the slope morphodynamics in the Phlegrean area. Mazzoleni et al. (2001) and Calcaterra et al. (2007) highlighted the role played by changes in land use and by wildfires as factors predisposing to landslides and erosion, especially on the slopes in the city of Naples.

The importance of human-related actions on local landslide activity is further evidenced by the historical data now available for the time period 1868-1985, which allow us to revise and update the data originally presented by Calcaterra et al. (2002).

For 98 out of the 150 inventoried historical events, the triggering causes have been identified (Fig. 7). Even if rainfall remains an important triggering factor, human activities hold an evident relevance, since about $20 \%$ of the old mass movements are attributed to quarrying activity and excavations; the latter factors, along with rainfall, contribute to another $59 \%$ of events.

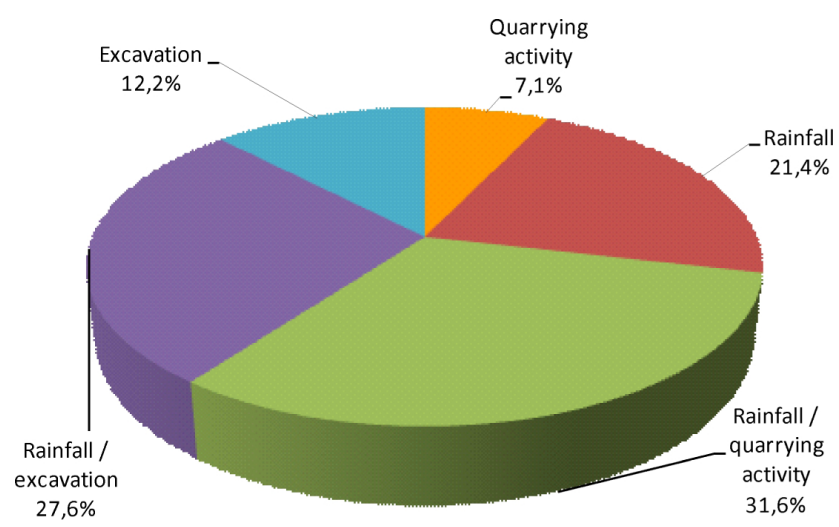

Fig. 7. Triggering factors of the 1868-1985 landslides at Naples (revisited and updated after Calcaterra et al., 2002).

Notwithstanding the pronounced difference in the number of data records, some interesting comments can derive from a comparison between the historical and the most recent data available for Naples (Figs. 8 and 9).

It can, in fact, be highlighted that lithology, type and geographical position of landslides have different values over time. In particular:

- mass movements involving the Neapolitan Yellow Tuff, bedrock formation for the whole territory of Naples, prevail in the 1868-1939 period, while the overlying, younger pyroclastic soils become the main lithology affected from 1940 onward;

- falls and topples are the prevailing type among the oldest landslides, an evidence which tends to decrease in the following decades, when slides, flows and slideflows emerge as the most common types; 

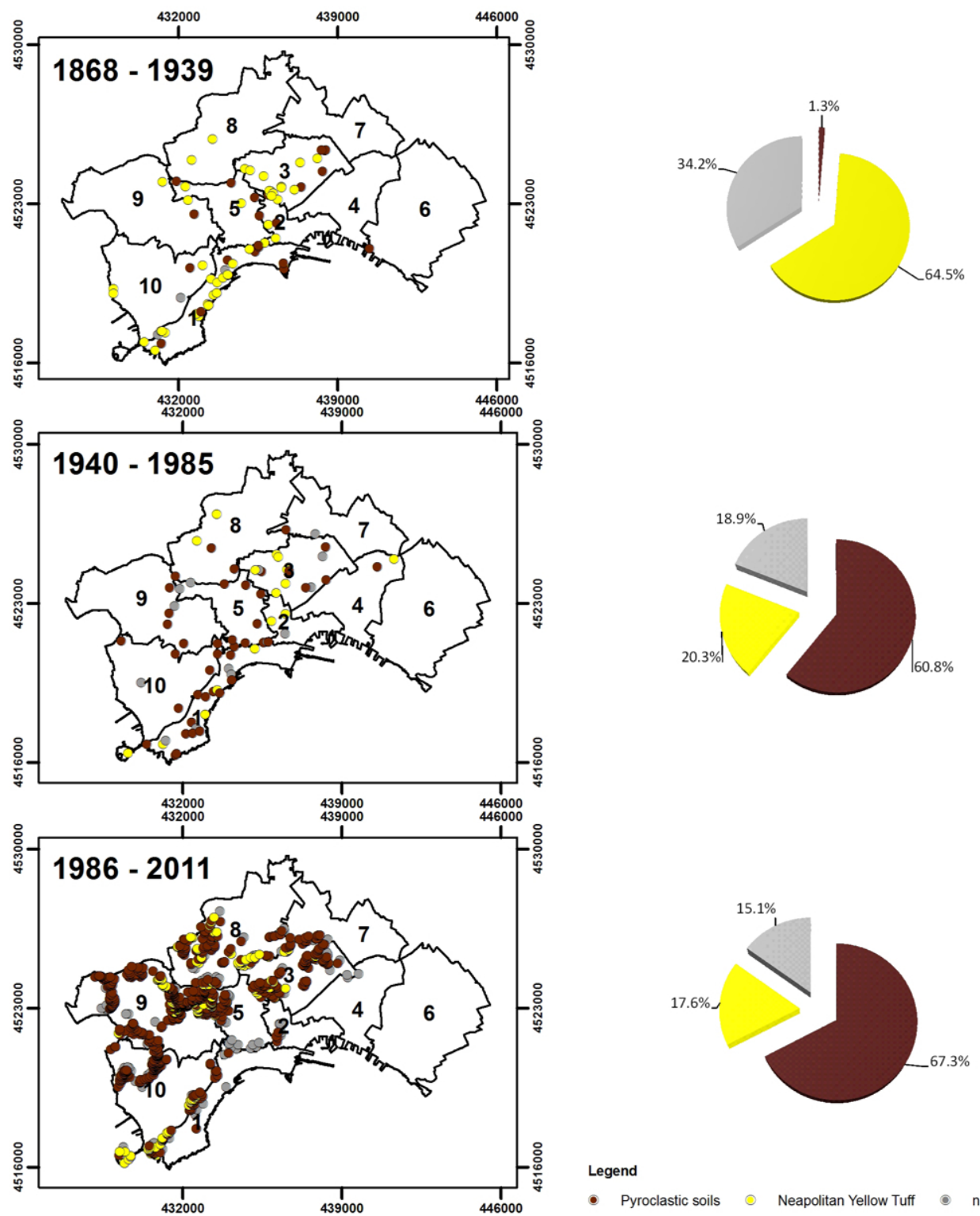

Legend

- Pyroclastic soils Neapolitan Yellow Tuff $\bigcirc$ n.d

Fig. 8. Temporal distribution of the Naples' landslides classified according to the lithologies involved (n.d. = unclassified).

- urban boroughs nr. 1 (Chiaia-Posillipo-S. Ferdinando) and 3 (San Carlo all'Arena-Stella) have been the focus for the oldest landslides; in more recent times, the boroughs which surround the Camaldoli Hill (nr. 9 - Pianura-Soccavo; nr. 8 - Chiaiano-PiscinolaMarianella-Scampia) have been more frequently hit by slope instabilities.

Cross-relating the above evidence to the triggering factors and bearing in mind some of the most important aspects of the urban evolution of Naples, a unifying explanation can be tentatively found, following a similar commentary already given by Calcaterra et al. $(2002,2007)$.
In the first place, it has to be noted that in the second half of the 19th century and in the first decades of the 20th century a flourishing quarrying activity was still carried out within the city boundaries, following a secular tradition, whose oldest examples are represented by the above cited underground tombs, dated to about 4.5 ka. According to Dell'Erba (1923), about 25 tuff quarries were exploited at the time, located in the Stella and Posillipo districts. In addition, on the Posillipo hill important infrastructures (e.g., Petrarca and Manzoni streets) and several buildings were realised from the end of the 19th century to, at least, World War II. On the contrary, the Camaldoli hill, historically interested by agricultural activities, was extensively involved in urbanisation, often illegal, in the second half of the 20th century, while, 

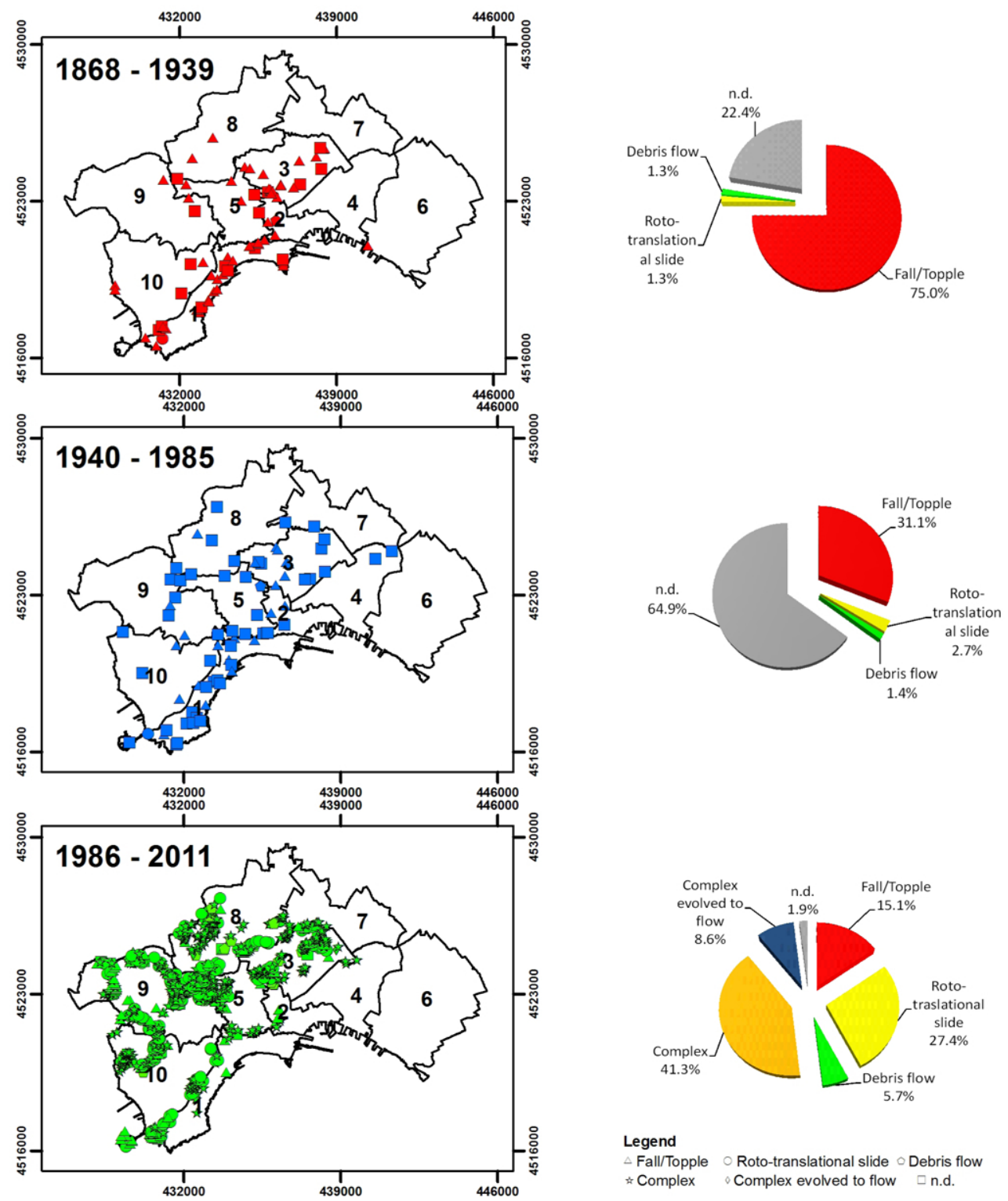

Fig. 9. Temporal distribution of the Naples' landslides classified according to their type (n.d. = unclassified).

in the same decades, cultivation on the slopes was rapidly abandoned, hence, causing a progressive decay in the stability conditions of the surficial, weathered portions of the loose pyroclastic deposits. As a consequence, the overall landslide pattern in Naples underwent relevant changes over time. In fact, past landslides involved essentially the tuff formations in those boroughs where more intense were the anthropogenic actions; in the last decades, mass movements tend to migrate towards boroughs historically hosting agricultural practices, whose abandonment, along with a wild urbanisation, favoured the onset of surficial rainfall-triggered instabilities involving the youngest, post-TGN loose pyroclastic terrains.
However, based upon the involved lithologies, two groups of mass movements can be recognised as typical of the slopes in Naples, and, more in general, of the Phlegrean continental area:

- the post-TGN loose pyroclastic terrains mainly feed slides on open slopes, which, only when follow short, structurally-controlled, low-hierarchized channels evolve into debris flows. Such landslides are prevailingly surficial $(<1 \mathrm{~m})$, initiate on slopes steeper than $35^{\circ}$ and show a limited runout potential (on average, $H / L=1$ - Calcaterra et al., 2004);

- the lithified tuffs are affected by falls and topples, which, predisposed by a typical columnar jointing, 


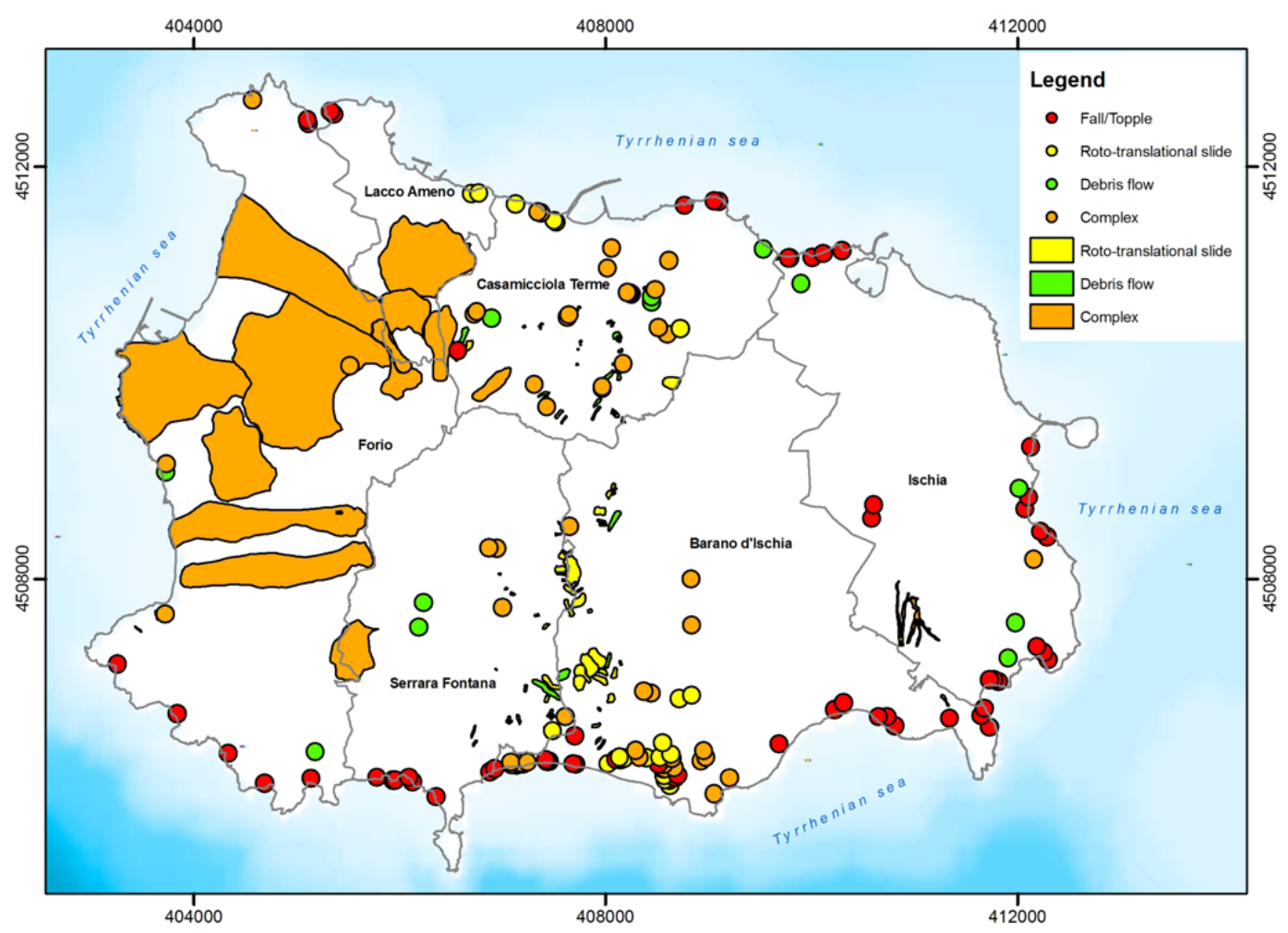

Fig. 10. Landslide-inventory map of the Ischia island. Submarine events are reported in Fig. 12.

move from high-angle cliffs and, more frequently, from cut slopes or quarry walls. These instabilities usually mobilize small volumes (from some cubic metres to a few tens), provided with a relatively low mobility.

\subsection{Landslides at Ischia}

Since the 1990s, various authors have dealt with slope instabilities of the Island of Ischia, which, thanks to rich archival sources, are now known since 4th century BC.

Accordingly, 288 single terrestrial events have been identified (Fig. 10), which involve all the six municipalities of the island. Among these events, 144 landslides, that occurred between 4th century BC and year 2002 and referred to 68 individual episodes, have been reconstructed by Del Prete and Mele (2006), while the remainders pertain to years from 2003 to 2010.

As shown in Fig. 10, the prevailing terrestrial landslide types are, similarly to the situation described for Naples, falls/topples, slides, flows and complex phenomena (mainly slides or falls evolving into flows). Most of the inventoried rock instabilities occurred along the coastal cliffs, which, as already highlighted by Del Prete and Mele (2006), denote a high-ranking susceptibility, if compared to other morphological settings (e.g., drainage-line banks, fault scarps, cut slopes).
Also for the island of Ischia it seems noteworthy to subdivide the landslide dataset on a temporal basis. In this case, two intervals have been defined only, taking due account of both the overall number of records and the temporal gap existing in the sources between 1924 and 1970 (Del Prete and Mele, 2006). Nevertheless, comparing old and recent phenomena, some apparent differences can be underlined, as regards to types of movements and lithologies involved (Fig. 11). While rock formations (tuffs and lavas) and ancient debris deposits are present in both periods, the pyroclastic soils, as already noticed for Naples, seem to be involved in mass movements especially in recent times. Consequently, slides and flows sensibly increase from old to recent times.

Moreover, it has to be added that the complex type holds a quite different meaning with time. In fact, complex movements that occurred in recent times are prevailingly given by surficial slides or small-scale rockfalls evolved into debris flows, while the old complex movements are represented by the huge landslide bodies of the western part of the Island. The latter were interpreted by Del Prete and Mele (2006) as deep-seated gravitational slope deformations associated to the volcano-tectonics of the island and, in particular, to the uplift of Mt. Epomeo, the major relief of the island.

The above evidenced differences between historical and recent instabilities can be explained analysing the related causal factors. Taking into account the dataset provided by Del Prete and Mele (2006), 40 events out of 68 have been 

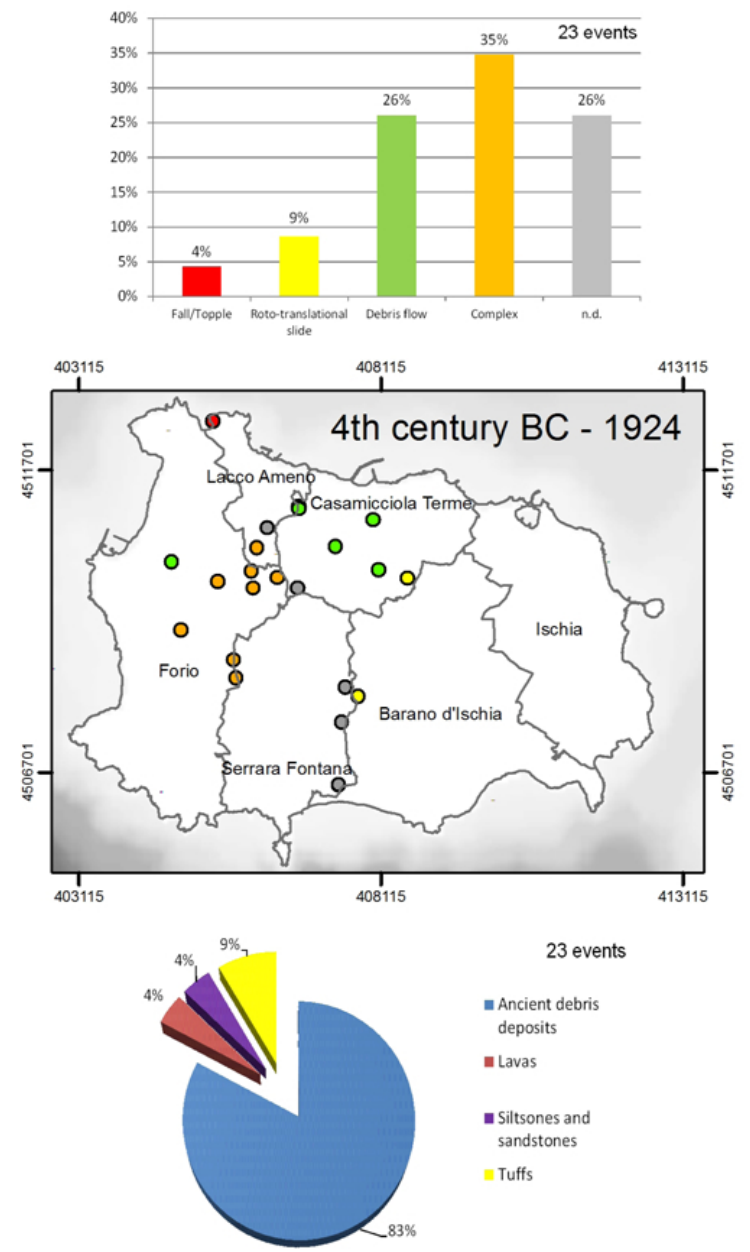
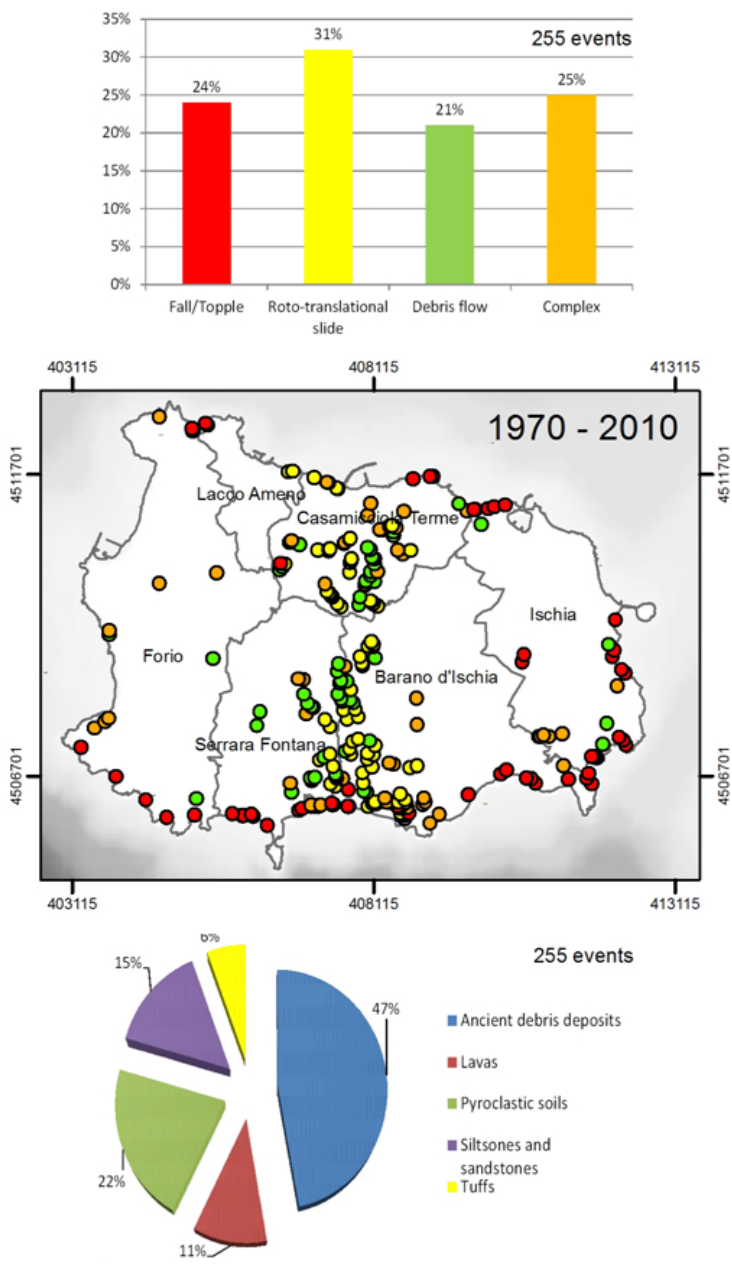

255 events

- Ancient debris deposits

- Lavas

= Pyroclastic soils

- Siltsones and

sandstones
Tuffs

Fig. 11. Temporal distribution of the terrestrial landslides in the island of Ischia. Histograms = landslide types; pie-charts =lithologies involved (n.d. = unclassified).

classified also in terms of their triggering cause: 14 refer to the 4th century-1924 period and 26 to 1970-2002. Among the oldest events, 9 out of 14 were associated to earthquakes (4th century BC, 3rd-2nd century BC, July 1228 , 1622, 2 February 1828, 14 February 1828, 30 January 1863, 4 March 1881, 28 July 1883) or eruptions (4th century BC) and the remaining 5 to rainfalls or sea-storms (second half of 16th century, June 1643, 1802, 7 May 1880, 24 October 1910). In the most recent period, on the contrary, all the inventoried events were related to either rainfalls or seastorms.

The prevalence in recent times of climate-controlled mass movements at Ischia is further confirmed by the latest instability history of the island, which has suffered severe consequences from at least three rainfall events, that occurred in 2006, 2009 and 2011, respectively (Fig. 6).

In addition to the terrestrial landslides, subaerial to submarine catastrophic collapses have been studied at Ischia. A first phenomenon (SDA in Fig. 12), that occurred at
Ischia in prehistorical times and was driven by the volcanotectonic uplift of Mt. Epomeo, has been recognised on the southern flank of the island by Chiocci et al. (1998) and Chiocci and De Alteriis (2006). The collapse generated a debris avalanche incorporating giant blocks dispersed as far as $50 \mathrm{~km}$ from the island and partially evolved into a debris flow covering an area of $250-300 \mathrm{~km}^{2}$. According to the authors, the major collapse was followed, and probably also preceded, by recurrent, less catastrophic terrestrial and underwater failures.

Offshore evidence of giant debris avalanches have been identified on the western and northern shelf areas as well (De Alteriis and Violante, 2009). The Western Debris Deposit (WDD in Fig. 12) covers an area of about $11 \mathrm{~km}^{2}$ and its volume has been estimated in 80 to $150 \times 10^{6} \mathrm{~m}^{3}$. The Northern Debris Deposits (NDD in Fig. 12), subdivided in two bodies, spread over an area of about $17 \mathrm{~km}^{2}$, while their inferred volume ranges between 0.2 and $0.6 \mathrm{~km}^{3}$. 


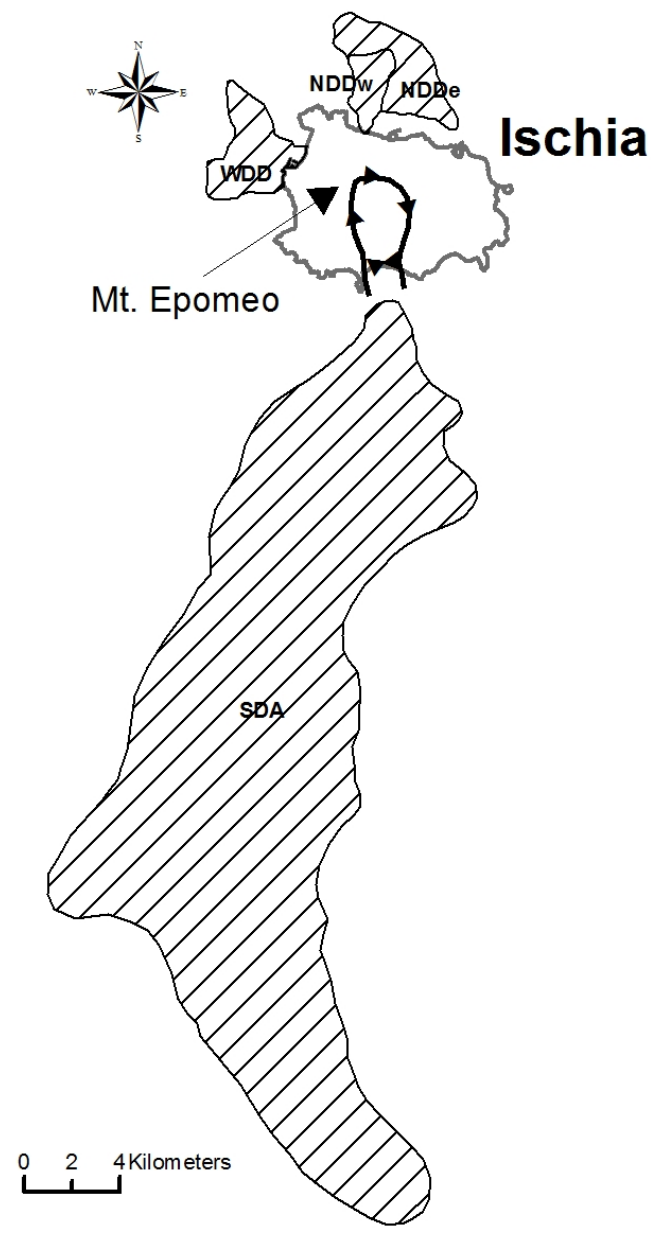

Fig. 12. Main submarine mass movements that occurred offshore of the island of Ischia (simplified and redrawn after Chiocci and De Alteriis, 2006; De Alteriis and Violante, 2009). SDA = Southern Debris Avalanche; WDD = Western Debris Deposit; $\mathrm{NDD}_{\mathrm{e}}=$ Northern Debris Deposit (eastern part); $\mathrm{NDD}_{\mathrm{w}}=$ Northern Debris Deposit (western part).

The age of emplacement of the submarine deposits has been inferred for the SDA only (time span ranging from 10 to $4 \mathrm{ka}$ ), while the NDD and WDD events have been generically ascribed to a Holocene age (De Alteriis and Violante, 2009).

Evident from Fig. 13, the mobility of the prehistorical submarine events is definitely higher than that displayed by the terrestrial landslides of the whole Phlegrean district. In fact, in the case of SDA, WDD and NDD, $H / L$ dramatically drops down to values between 0.03 and 0.12 , being related to runout distances from 7 to $45 \mathrm{~km}$ and to vertical heights of the collapsed areas varying between 800 and $1500 \mathrm{~m}$.

De Alteriis and Violante (2009) have also pointed out that the prehistorical events are likely to have produced tsunami waves spreading across the Tyrrhenian Sea and possibly into the Bay of Naples.

\section{Landslide hazard and risk}

Italy has a long history of landslide disasters, whose first nation-wide report was written by the geographer Roberto Almagià at the beginning of the 20th century (Almagià, 1907, 1910). Nevertheless, despite a mournful sequence of catastrophic events (e.g., Salerno, 1954: 300 victims; Vajont, 1963: about 2000 victims; Val di Stava, 1985: 268 victims; Val Pola, 1987: 27 victims), it was only in 1989 that the first law on land management and soil protection was promulgated (law nr. 183/1989). However, another decade had to pass and, above all, another huge tragedy had to occur (Sarno and four more towns, May 1998: 160 victims) as to give full implementation to the law nr. 183, assigning tight deadlines to the Basin Authorities (BAs), governmental agencies in charge of land planning and management. The main task assigned by law to BAs was the set-up of the Basin Plan, a comprehensive planning act, dealing with different territorial and environmental issues, such as landslides, floods, groundwater, coastal erosion, etc., each of which treated in detail with specific thematic maps, rules for land use, etc. As regards to landslide and flood risk, the BAs, ranked in three levels (national, interregional and regional), started their work soon after the tragedy of Sarno, initially working at a landslide and flood Emergency Setting Plan (ESP), aimed at identifying, through a heuristic approach, those areas falling within the highest risk levels, hence R3 (high) and R4 (very high).

In the following years, BAs went on with the implementation of a Hydrogeomorphological Setting Plan (HSP - Sorriso Valvo, 2005), one for each BA. Consequently, Italy became one of the very few countries in the world entirely covered with landslide and flood risk maps, where the risk is ranked in four levels from R1 (low risk: possibility of limited damage to persons and property) to R4 (very high risk: possibility of loss of human life and irreparable damage to property).

The territory of Naples and the Island of Ischia is managed by the Basin Authority of Northwestern Campania Region (BANCR), whose jurisdiction extends over about $1500 \mathrm{~km}^{2}, 127$ municipalities and around 3 million inhabitants. BANCR issued its ESP in 1999 and the first release of its HSP in year 2002, revising it in 2010; ESP was at a 1:25000 scale, whereas both versions of HSP were produced at a 1:5000 scale. The procedure followed to obtain the final landslide risk map has been extensively described by $\mathrm{Cal}-$ caterra et al. (2003a - Fig. 14) and critically reviewed by Sorriso Valvo (2005). It is based on two intermediate maps, Landslide Detachment and Runout Susceptibility maps, taking into due account the peculiar features of the territory and of its landslides. In fact, among the 2333 terrestrial historical and recent landslides inventoried by the BANCR, the large majority is represented by slides and flow-like-movements involving the Late Pleistocene-Holocene loose pyroclastic deposits of either Vesuvian or Phlegrean origin. 

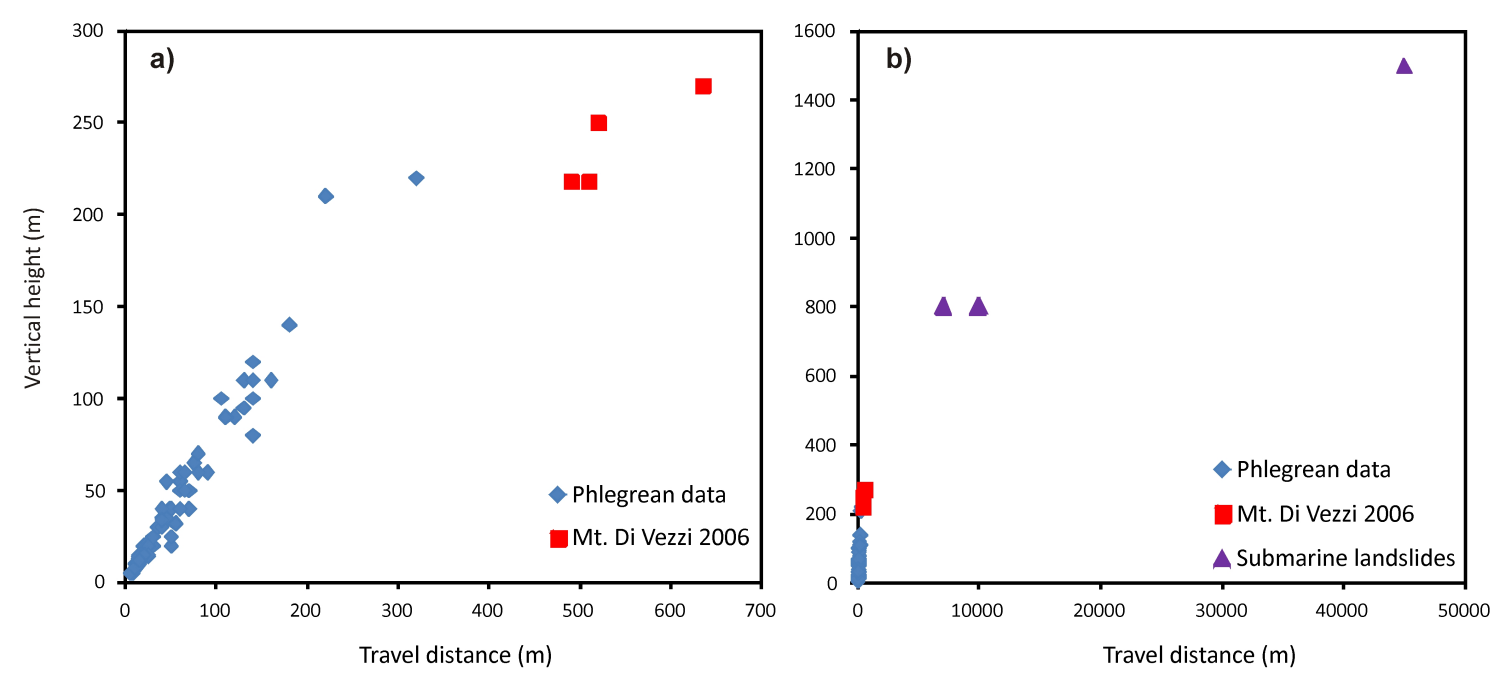

Fig. 13. Relationships between vertical height and travel distance for the flow-like movements that occurred in the Phlegrean Fields: (a) terrestrial events; (b) terrestrial and submarine events.

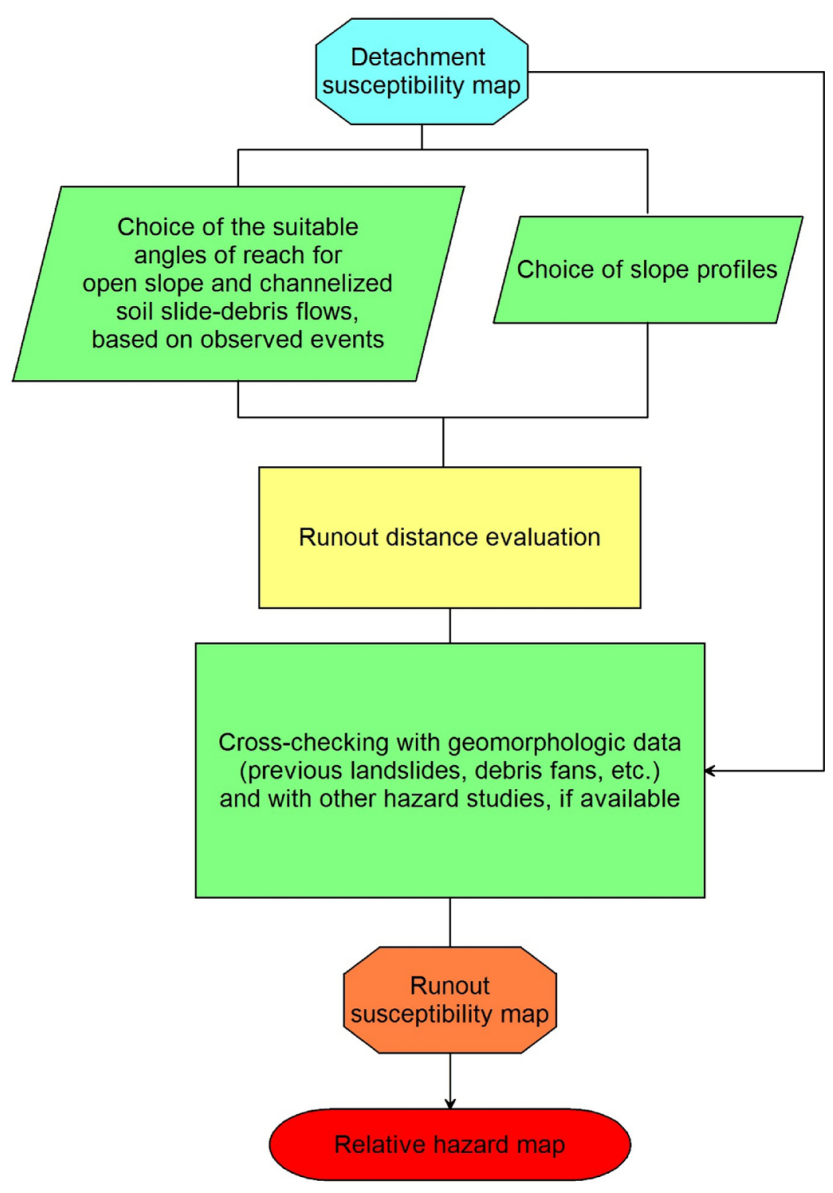

Fig. 14. General procedure adopted to create the Landslide Relative Hazard map of the BANCR (after Calcaterra et al., 2003a modified).
The Detachment Susceptibility map is based upon a statistical analysis of some factors relevant to the onset of the above types of mass movements, cross-correlating the frequency of detachment areas and slope gradient $(S)$, thickness of pyroclastic cover $(T)$, distance to tracks/roads $(D)$ and land use $(L)$. The parameters $S, T$ and $D$ are expressed as percent frequency and probability, whereas $L$ is an aggravating factor (therefore, greater or equal to one). The general expression, in the form $I=\left[S^{(1+T+D)}\right] \times L$, is subsequently adapted to the main geological and geomorphologic settings (Vesuvian area, Phlegrean area, carbonate ridges) using or discarding some of the cited parameters (Calcaterra et al., 2003a).

Among the factors considered in the source areas, slope gradients are well known as a clear indicator of landslide susceptibility. In the Phlegrean district initiation of slides prevailingly occurs on slopes with gradients between $30^{\circ}$ and $65^{\circ}$ with a mean value of $46^{\circ}$ (Calcaterra et al., 2004b). Slope maps (Fig. 15) put in evidence the key-role played in predisposing the slopes of the studied areas to instability. In fact, at Naples, about $14 \%$ (ca. $16 \mathrm{~km}^{2}$ ) of the urban territory falls in the $31^{\circ}-45^{\circ}$ and $46^{\circ}-65^{\circ}$ classes, while at Ischia gradients lower than $30^{\circ}$ characterise only $53 \%$ of the island's territory.

The Runout Susceptibility map is based on a geomorphological approach, which in turn considered the "angle of reach", first introduced by Heim in 1932 while analysing some catastrophic landslides in the Alps (stürzstroms or rock avalanches). As known, the angle of reach (fahrböschung) is the line connecting the head of the landslide source to the distal margin of the displaced mass. In this case, the $H / L$ relationship was considered only, given that data on the volume of displaced material were not available for the entire territory. Different angles of reach were adopted, with reference 


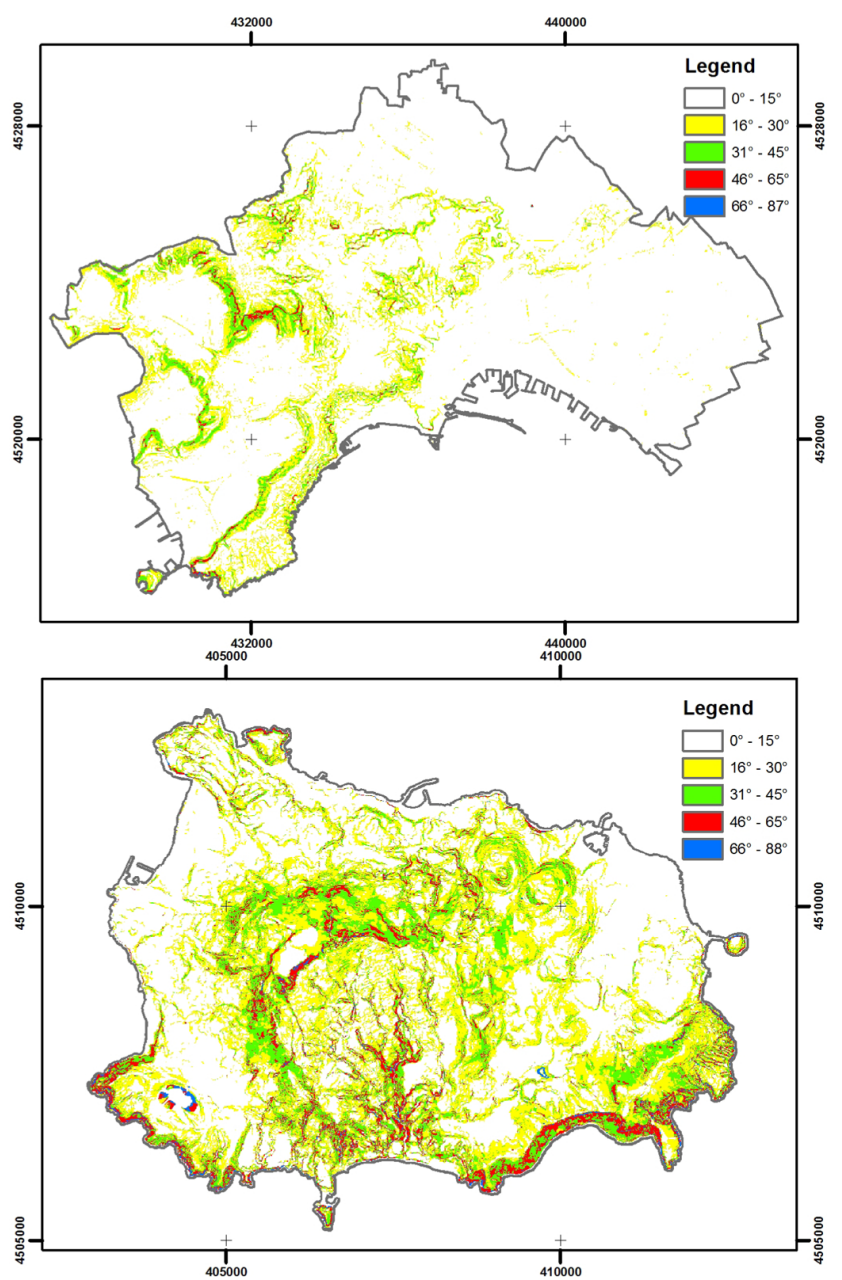

Fig. 15. Slope maps of Naples (above) and Ischia island (below).

to the above cited settings, and considering either open-slope or channelised slope movements. However, BANCR maps take into account terrestrial, historical to recent landslides only. Accordingly, the Holocene subaerial to submarine instabilities that occurred at Ischia were not considered in the Runout Susceptibility map. The latter was based, for the Phlegrean district, upon the data shown in Fig. 13a.

By integrating Landslide Detachment and Runout Susceptibility maps the Relative Hazard map was obtained, structured on three grades $(\mathrm{P} 3=$ High, $\mathrm{P} 2=$ Medium, $\mathrm{P} 1=$ Low $)$. "Relative Hazard" was intended, following Hartlèn and Viberg (1988), to express the occurrence of mass movements for different areas on the map without giving exact values. In particular, in the maps of BANCR a relative prediction of the location, typology, intensity and evolution of the landslides is given, without predicting their temporal occurrence, since no reliable estimation of recurrence intervals was possible (Calcaterra et al., 2003a). Noteworthy to add is that all the official Italian risk maps are based on the relative hazard concept, being all characterised by the same drawback concerning the temporal distribution of landslides.
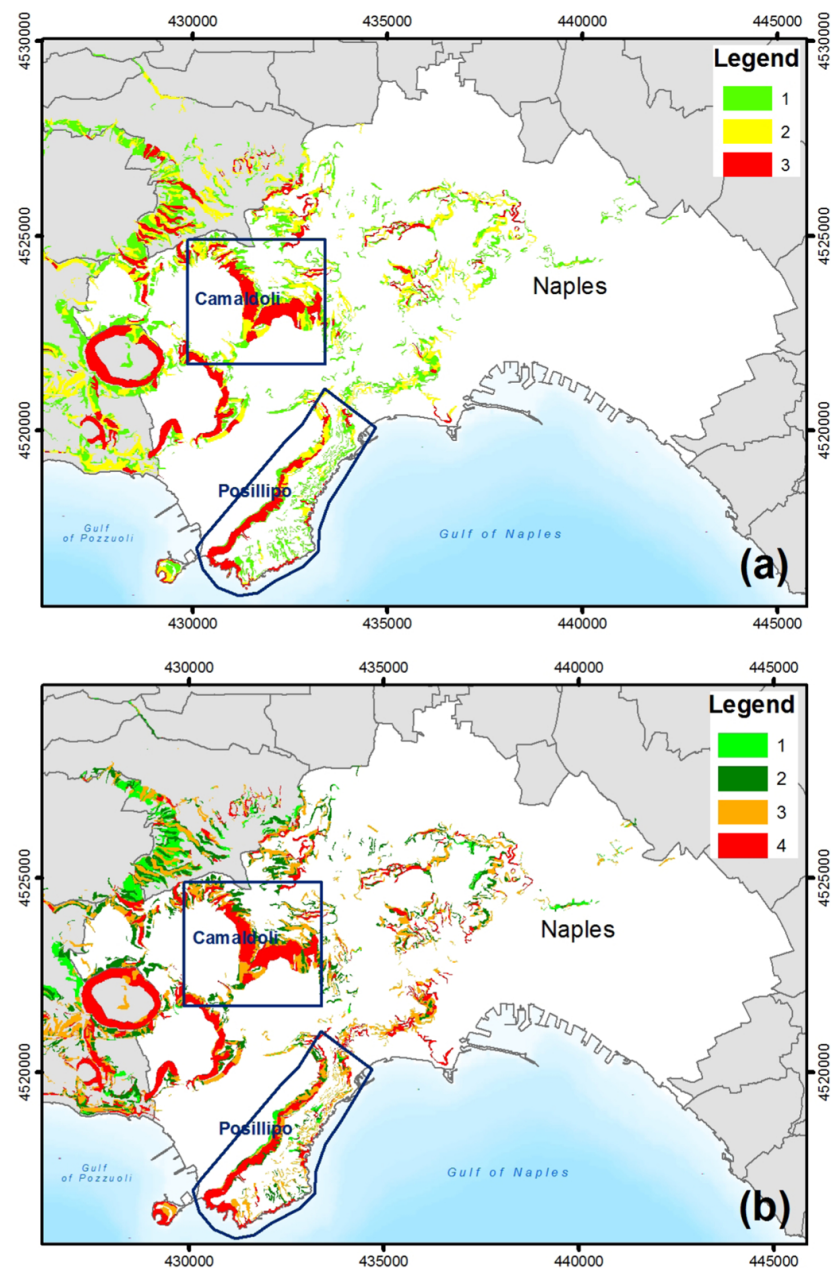

Fig. 16. Relative hazard (a) and risk (b) maps of Naples (after BANCR, 2010, modified). Hazard map legend: (1) low relative hazard; (2) medium relative hazard; (3) high relative hazard. Risk map legend: (1) moderate risk; (2) medium risk; (3) high risk; (4) very high risk.

Finally, the Landslide Risk Map was obtained overlying the Landslide Relative Hazard Map and the Potential Damage Map, the latter defined as the expected loss of property and/or human life; Potential Damage (D) is the product of the Exposed Value (E) and Vulnerability (V) and is ranked according to four levels. The resulting risk is hence assessed through a $3 \times 4(\mathrm{P} 1, \mathrm{P} 2, \mathrm{P} 3 \times \mathrm{D} 1, \mathrm{D} 2, \mathrm{D} 3, \mathrm{D} 4)$ matrix.

The land classification for the city of Naples and for the island of Ischia is reported in Figs. 16 and 17, respectively. In Naples, $27 \%$ of territory is exposed to the three levels of landslide relative hazard; at Ischia, the percentage is twice as high, reaching $54.2 \%$ of the total surface $\left(\right.$ ca. $46 \mathrm{~km}^{2}$ ). In terms of landslide risk, at Naples almost $24 \mathrm{~km}^{2}(21 \%)$ fall in the high (R3) and very high (R4) grades, while at Ischia $44 \%$ of the island's territory pertains to the two worst risk classes. 


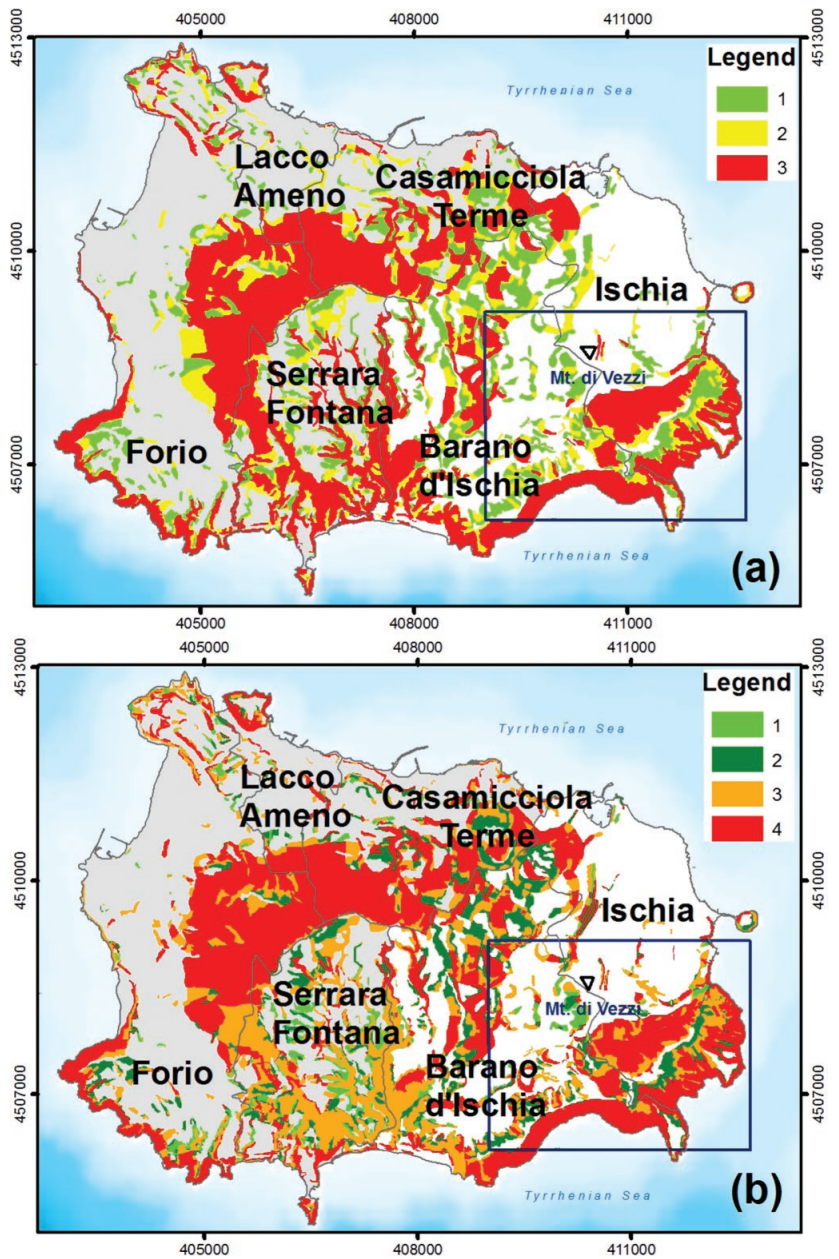

Fig. 17. Relative hazard (a) and risk (b) maps of the Ischia island (after BANCR, 2010, modified). Hazard map legend: (1) low relative hazard; (2) medium relative hazard; (3) high relative hazard. Risk map legend: (1) moderate risk; (2) medium risk; (3) high risk; (4) very high risk.

Taking our fair knowledge of landslides in the study areas as a starting point, a research was carried out on the urbanisation process, focusing on some selected zones of Naples and Ischia. To this scope, several topographical maps have been selected, covering more than $200 \mathrm{yr}$, where the urban setting was in good evidence, so as to allow its extraction from the maps into a GIS; by doing so, the single buildings have been transferred from the original older maps to the most recent one, represented by the Regional Technical Map (RTM - scale 1:5000, year 2005), available in digital format. As for Naples, maps dated 1790, 1800, 1837-1848, 1907, 1955, 1965, 1968, 1980, 1987, 2005 were used; in the case of Ischia island, the available maps were dated to the years 1885, 1965, 1974, 1984 and 2005. Eventually, the number of edifices present in the studied areas was counted within an assigned time interval and cross-related with the BANCR Landslide Susceptibility Map.
This procedure was adopted as an indirect way of evaluating a "societal perception" of the landslide hazard with time, considering that both at Naples and Ischia landslide events were experienced by citizens since, at least, the 19th century. The selected areas of Naples (Posillipo and Camaldoli) were chosen based on the great number of landslides which affected their slopes. At Ischia, the south-eastern portion of the island was chosen: here, the $2006 \mathrm{Mt}$. di Vezzi landslides took place, which represents the worst single episode of the recent landslide history of the island.

In the case of Naples, 2744 building are nowadays present in the Posillipo test-area (Figs. 18 and 20) and 4879 around the Camaldoli hill (Figs. 19 and 20). Comparing the two areas, the temporal distribution of buildings is uneven and reflects their different urban evolution. At Posillipo about $9 \%$ of edifices had been built before 1800 , reaching $17 \%$ at the beginning of the 20th century. The urbanisation of the boroughs surrounding the Camaldoli hill, as said above, is more recent and has a certain relevance in the pre- and post-World War II years, considering that, after an initial $4 \%$ already present in 1848, the figure rises up to $19 \%$ in the 1965 map. Accordingly, the relative urban expansion occurs in different periods (Fig. 20), since at Posillipo $35 \%$ of buildings were already present in 1964 and a further $46 \%$ between 1965 and 1984. Conversely, urbanisation in the Camaldoli boroughs begins during the 1960s (10\% from 1965 to 1968) and explodes from the 1980s onward (1985-2005: 56\%).

The situation in the southeastern portion of the island of Ischia is slightly different, since $70 \%$ of the buildings mapped in 2005 (5372) were erected in the 1965-1984 period (Fig. 21). When the single maps are considered (Fig. 20) it can be seen that the increase which occurred in the first $80 \mathrm{yr}$ had already been quite high (1885-1964: +216\%). Nevertheless, it quadruples in the last $45 \mathrm{yr}$, with a $+838 \%$ from 1964 to 2005: this value falls in the interval reported by Monti (2006).

Of the 5372 buildings existing at Ischia in 2005, $31 \%$ (1670) are exposed to the three grades of landslide relative hazard $(\mathrm{P} 1=47 \% ; \mathrm{P} 2=22 \% ; \mathrm{P} 3=31 \%)$. Also in this case, the growth is very far from being linear. In fact, from 1885 to 1964 less than $20 \%$ (19.1\%) of the new buildings fell in one of the hazard levels, while the remaining $80 \%$ was built from 1965 to present-day. As a consequence, bearing in mind that to each building BANCR assigned the maximum level of potential damage (D4), $47 \%$ of the vulnerable edifices falls in the high risk class and $53 \%$ in the very high risk class.

In the two study area of Naples, figures related to the landslide hazards are quite different, since at Posillipo $39 \%$ of the buildings (with a peak in the 1960s) are located in the P3-P2-P1 zones, while in the Camaldoli boroughs the global percentage drops down to $8 \%$. Some reasons can be tentatively invoked to explain such a difference. First of all, it has to be noticed that the main settlements of the Camaldoli hill are concentrated on the top highplain and on the basal plains 

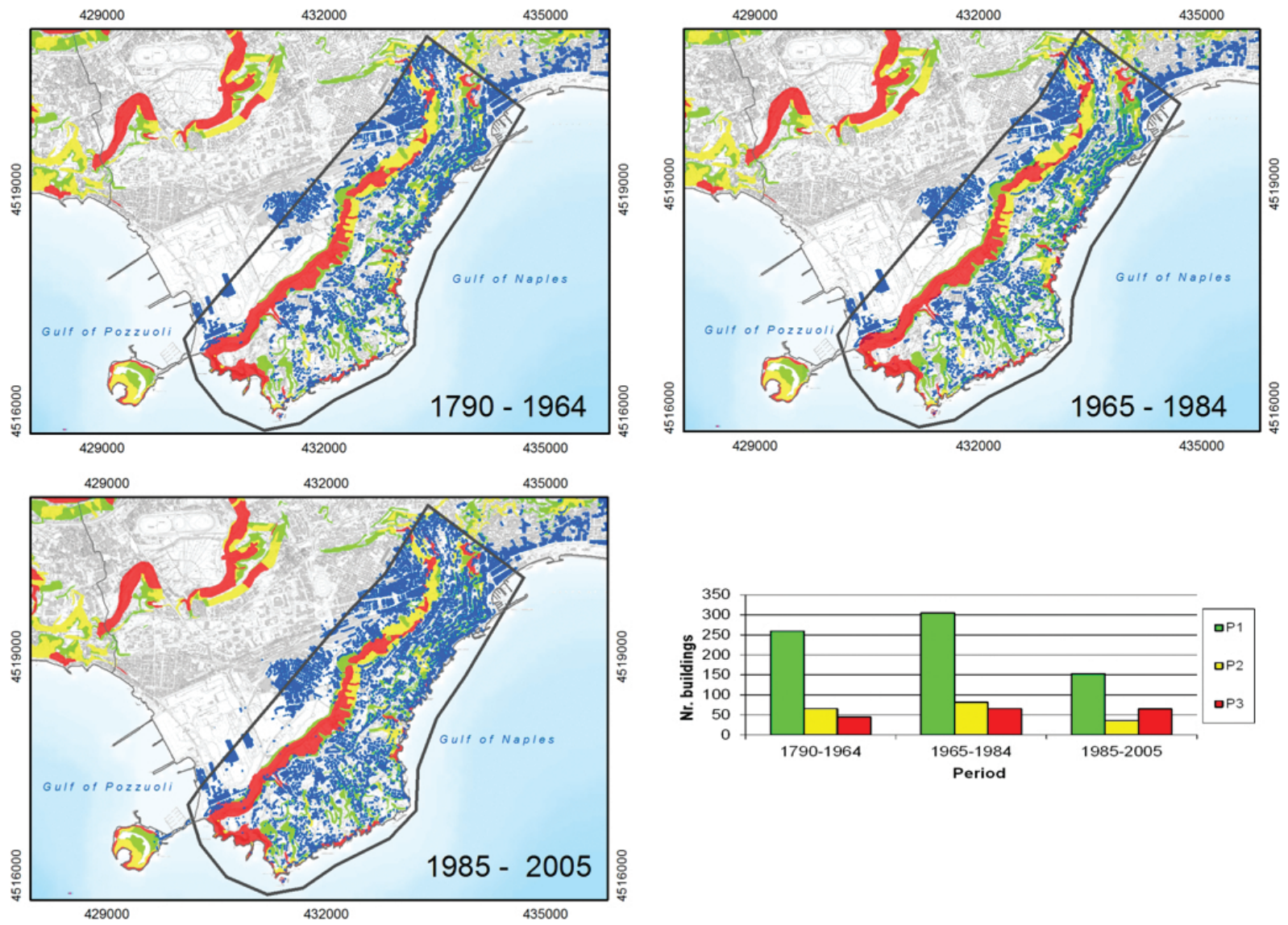

Fig. 18. 1790-2005 temporal distribution of the dwellings built at Posillipo, Naples. Key to symbols: $\mathrm{P} 1=$ low relative hazard; $\mathrm{P} 2=$ medium relative hazard; $\mathrm{P} 3=$ high relative hazard.

located at a certain distance from the foothill (Fig. 1); on the contrary, no relevant settlement has been built along the Camaldoli slopes (Fig. 1). At Posillipo, the urbanisation developed not only on the top of the hill or at its base, but also along the slopes (Fig. 22). This was favoured, since 19th century, by the opening of some winding roads, running across the hill from one edge to the other. Moreover, the search of a scenic position on the eastern, sea-facing side of the hill, often resulted in highly vulnerable locations at the foot of high-angle slopes cut in TGN.

Notwithstanding the above differences, both at Posillipo and, even more, at Camaldoli, in recent years many buildings have been realised in unsafe places (Fig. 20), a behaviour that, similarly to what happened at Ischia, denotes a "loss of memory" of the preceding instability history.

\section{Discussion}

In the above sections, it has been evidenced that Naples and the island of Ischia have experienced a long series of small-scale, low-mobility, fast terrestrial landslides which resulted in the prediction of a high susceptibility. However, the landslide susceptibility as predicted by BANCR should be complemented by relevant information on the prehistorical, high-mobility, subaerial to submarine giant debris avalanches analysed in some recent papers: in fact, for these events, a tsunamigenic potential has been highlighted (De Alteriis and Violante, 2009).

The issue of a volcano-related tsunami hazard in the Mediterranean basin has been recently critically reconsidered after a relatively small avalanche (ca. one million $\mathrm{m}^{3}$ ) that occurred at Stromboli, one of the Eolian islands, on 30 December 2002: on that occasion, a 3-4 m high tsunami wave was generated, which partially inundated some coastal sectors of the island, also reaching the coast of the Tyrrhenian regions of southern Italy (Tinti et al., 2003).

However, in the case of Ischia, the main cause of the largescale onshore and offshore instabilities was the fast volcanotectonic uplift of Mt. Epomeo, which, averaged over $30 \mathrm{ka}$, has been evaluated at $20 \mathrm{~mm} \mathrm{yr}^{-1}$, with possible higher values during shorter time spans (Luongo et al., 2008; De Alteriis and Violante, 2009). On the contrary, since at least the last destructive 1883 earthquake, Ischia is experiencing a downlift trend, which, in the last decades, displayed values 

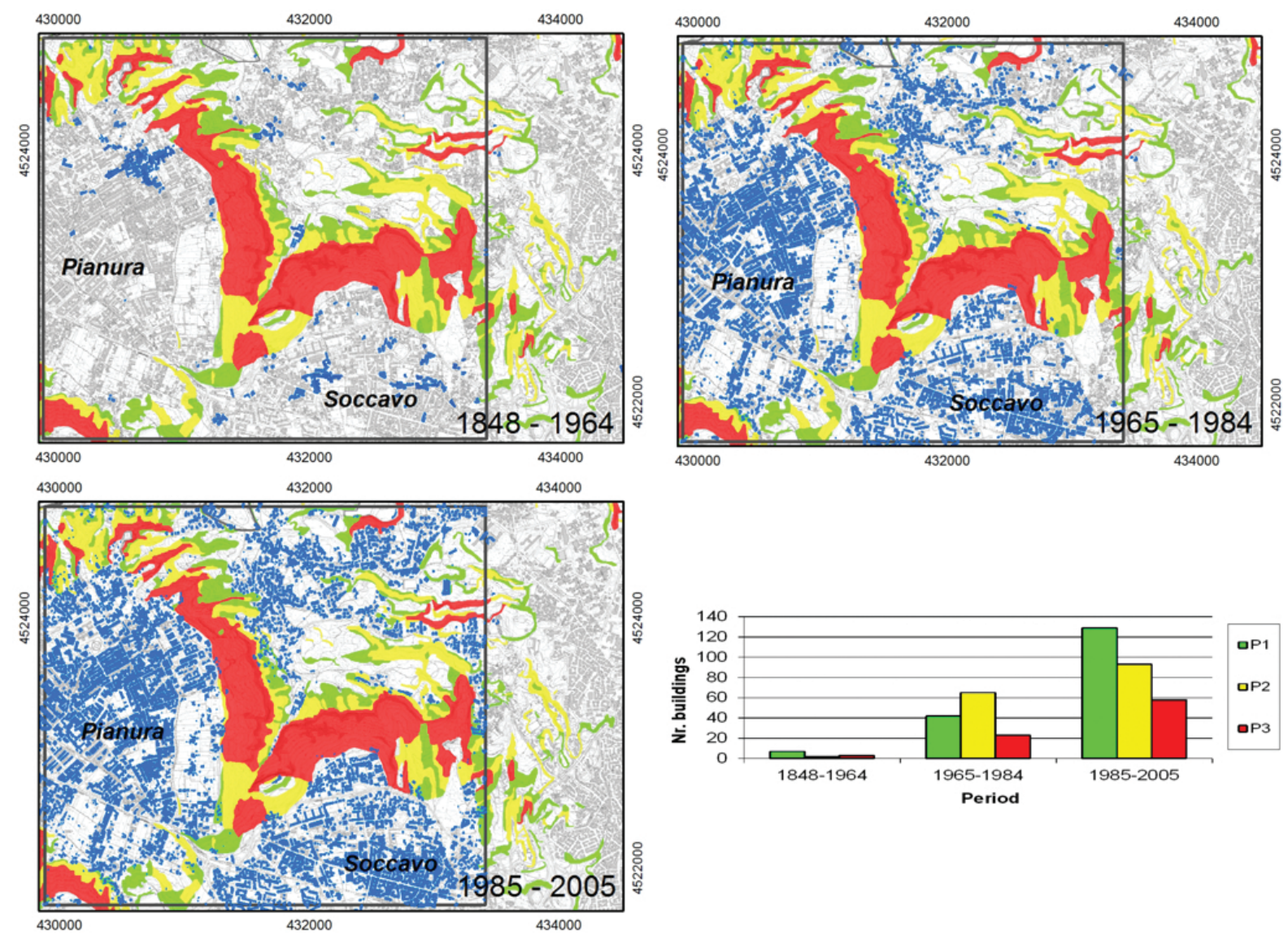

Fig. 19. 1848-2005 temporal distribution of the dwellings built around the Camaldoli hill, Naples. Key to symbols: P1=low relative hazard; $\mathrm{P} 2=$ medium relative hazard; $\mathrm{P} 3=$ high relative hazard.

from about 5 to $8 \mathrm{~mm} \mathrm{yr}^{-1}$ (http://www.ov.ingv.it). Therefore, the present-day tsunamigenic potential at Ischia is an issue which deserves further efforts and specific in-depth studies.

Along with the diffused landslide susceptibility, this study has evidenced the increased landslide-related vulnerability of the studied territories. This tendency can find a comprehensive explanation in the complex dynamics of the various laws and rules which, both at local and national level, should have guided and controlled the urban development over the years.

The urban sprawl of Naples from the end of the 19th century onward has been extremely intense, even though characterised by variable features. Firstly limited and quite disciplined, after the huge damage suffered during World War II the urban expansion became very fast and intense, responding to an urgent need for housing. Unfortunately, the lack of precise urban planning and building regulations, or their infringement, has resulted in a chaotic urban evolution.

In the General Master Plan enacted in 1922, Naples was described as a hilly city, which, stretching along the coast, could not expand in all directions, but was forced to develop around various centres, adapted to the morphological constraints. For this reason, the initial urbanisation of the
Neapolitan hillsides was based on isolated villas or limited blocks of small buildings; such a tendency was again confirmed in 1933-1934, in a study finalized to a new Master Plan, where the need for a better quality of urban life was underlined (Di Lorenzo, 2006).

In 1939, the Municipality of Naples decided to redact a new Master Plan, thus, anticipating the national Town Planning Act of 1942. Although it was considered one of the most interesting products of the urban planning culture of that period, it was soon disregarded and since 1944 the need for a new Plan was forwarded (De Lucia and Jannello, 1976). This status favoured for about $30 \mathrm{yr}$ the illegal occupation of urban spaces on behalf of both contractors and politicians, obviously sustained by the local mafia-like criminal organization ("camorra"). Even after the 1972 Plan, the situation went on, this time due to the total absence of control on behalf of the public authorities, which tolerated citizens to disregard local and national laws. This resulted, in particular for the hillsides, in a devastating aggression, paired by a contemporary abandonment of the agricultural practice, even though the 1939 Master Plan had already foreseen the setting of a natural reserve within the Camaldoli hill (Di Lorenzo, 2006). 
Posillipo
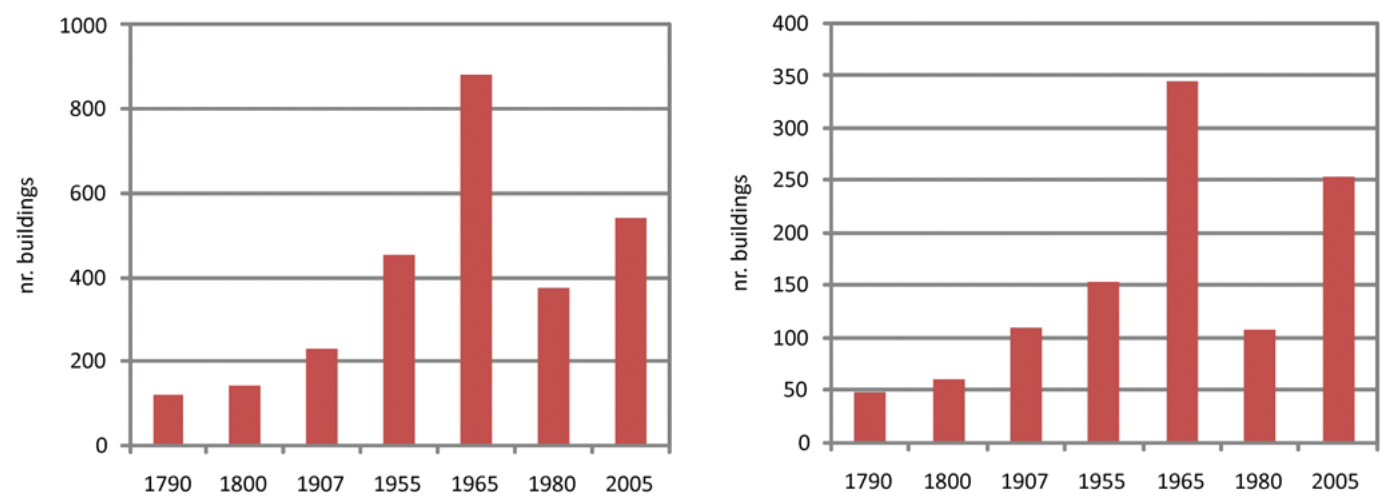

Camaldoli
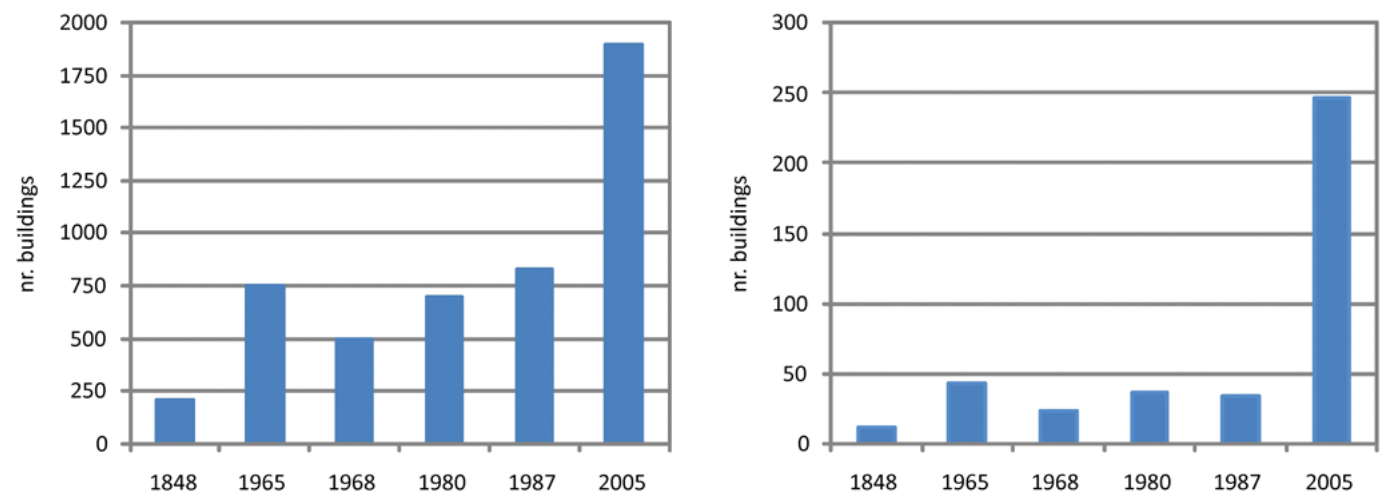

Ischia
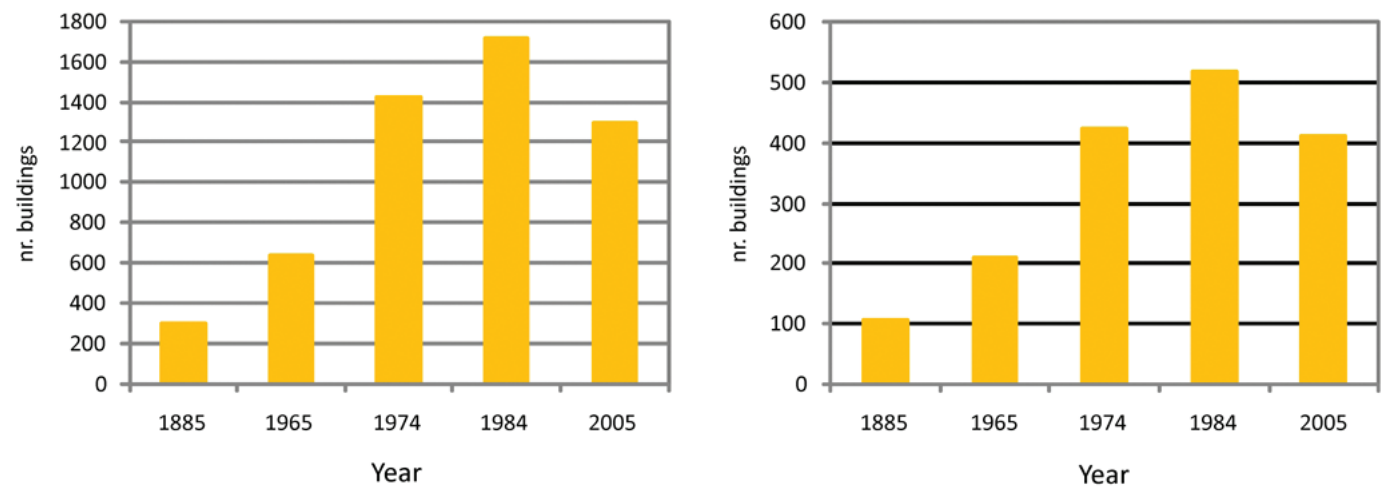

Fig. 20. Temporal distribution of buildings realised in the whole study areas (left) and in at-risk zones (right).

It was only in 1995 that a specific Landscape Planning Act strictly ruled the land-use of the western hillsides of Naples (Camaldoli, Posillipo, Agnano), followed in 1999 by the ESP and in 2002 by the HSP, both enacted by BANCR. Both plans introduced severe restrictions for all the areas exposed to either landslide or flood risk, making much more difficult any intervention on the slopes and in the surrounding zones. Nevertheless, in the last decade, the occupation of unsafe places for building purposes went on.

Similar circumstances affected the island of Ischia, further complicated by the administrative subdivision in six different municipalities; in Italy, the municipalities are entities acting with autonomous powers in the matter of urban planning and management. To this regard, it seems sufficient to note that in the year 2001 two of the six municipalities (Barano and Forio) had not approved their Master Plan yet.

The critical situation briefly depicted for Naples and Ischia is common to vast areas of the Italian territory, especially in the poorer regions of south Italy.

In 2007, Legambiente, an Italian Non-Governmental Organization, published the results of a nation-wide study (Fiorillo et al., 2007) on the life-quality in the 103 Italian 

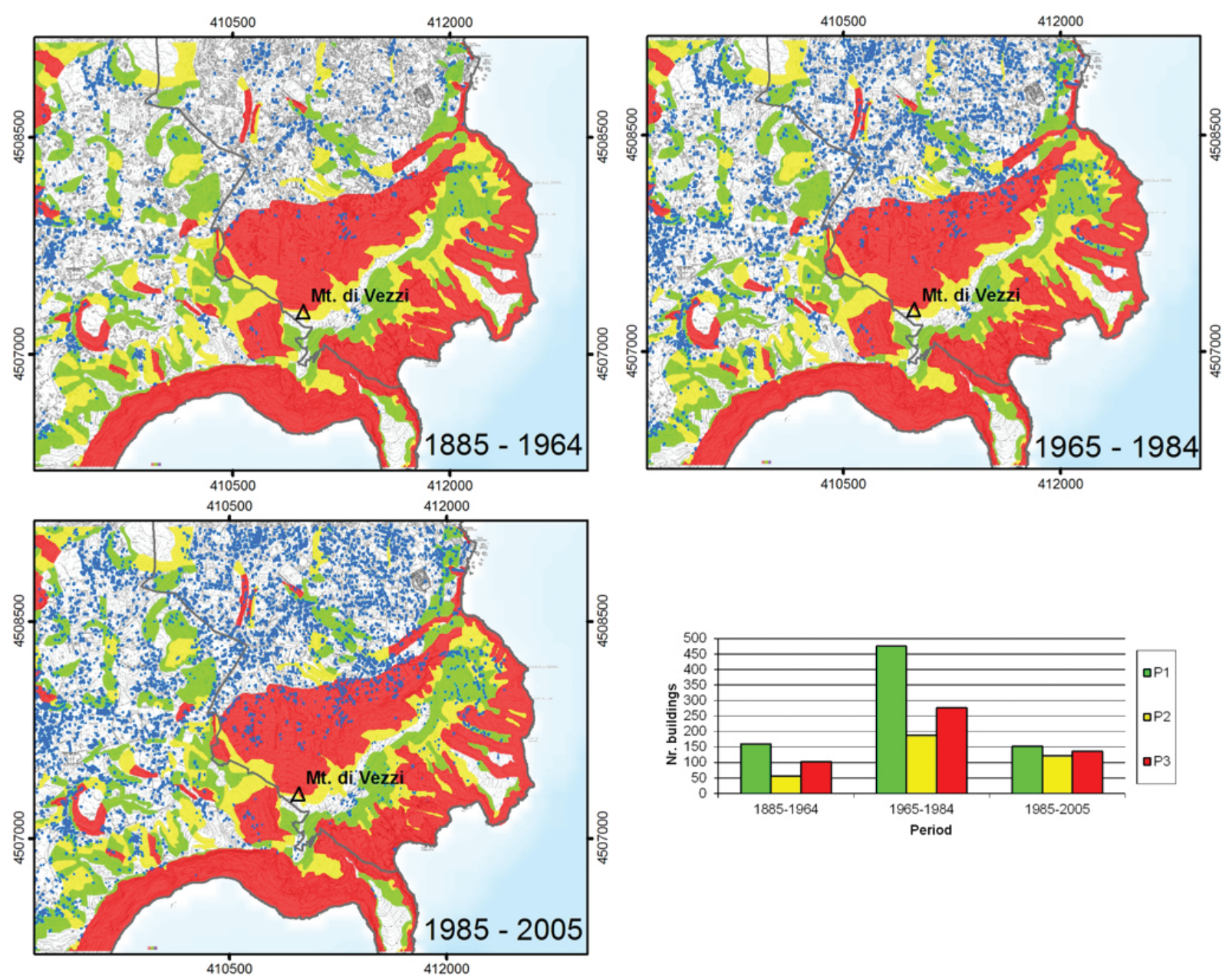

Fig. 21. 1885-2005 temporal distribution of the dwellings built in the southeastern part of the Ischia island. Key to symbols: P1 = low relative hazard; $\mathrm{P} 2=$ medium relative hazard; $\mathrm{P} 3=$ high relative hazard.

province-capitals. $55 \%$ of the new illegal buildings realised from 2006 to 2007 were located in the southern regions of Italy, among which Campania stood first with 7690 edifices, followed by Sicilia (5516), Puglia (4958) and Calabria (3788). In Naples, 13 illegal buildings for every 10000 inhabitants were present, a figure which rose up to almost 19/10000 in other seven towns of south Italy. In the same report, further interesting data can be found, such as the number of illegal buildings realised in Italy between 1994 and 2003 (402 676) and the peak annual value reached in year 1984 with 125000 unauthorized edifices.

But, strange as it may seem, the Italian governments of the last $30 \mathrm{yr}$ have systematically decided not to take any adequate initiative against the endemic illegal construction, but, on the contrary, to indirectly encourage it through a system of retrospective planning permissions. Three building amnesties have been, in fact, promulgated in 1985, 1994 and 2003, allowing people to declare their infringements to building regulations, pay a fee and be absolved for their illegal construction.
If in the case of Naples the number of applications is countless (probably more than 100000 ), at Ischia, according to Legambiente, after the 2003 building amnesty only, there were nearly 9000 requests for pardons on the island, whose resident population is about 56000 .

Also the BAs' restrictions for the areas classified as vulnerable to landslides and floods, introduced since 1999, remained unapplied. Again, a good example comes from the studied areas. At Ischia, the house destroyed by the 2006 Mt. di Vezzi landslides was illegal even if located in an R4 area: its owner died while he was still waiting for a building amnesty.

The study areas suffer from a number of adverse natural factors which predispose slopes to instability (e.g.: loose pyroclastic resting upon high-angle slopes; weak, jointed tuffs). In addition, human activities have aggravated either slope propensity to landsliding (e.g.: abandonment of agricultural practices) or the severity of landslide-related effects. In this latter respect, Naples and the Ischia island have undergone a pronounced increase in vulnerability to landslides, as a direct 


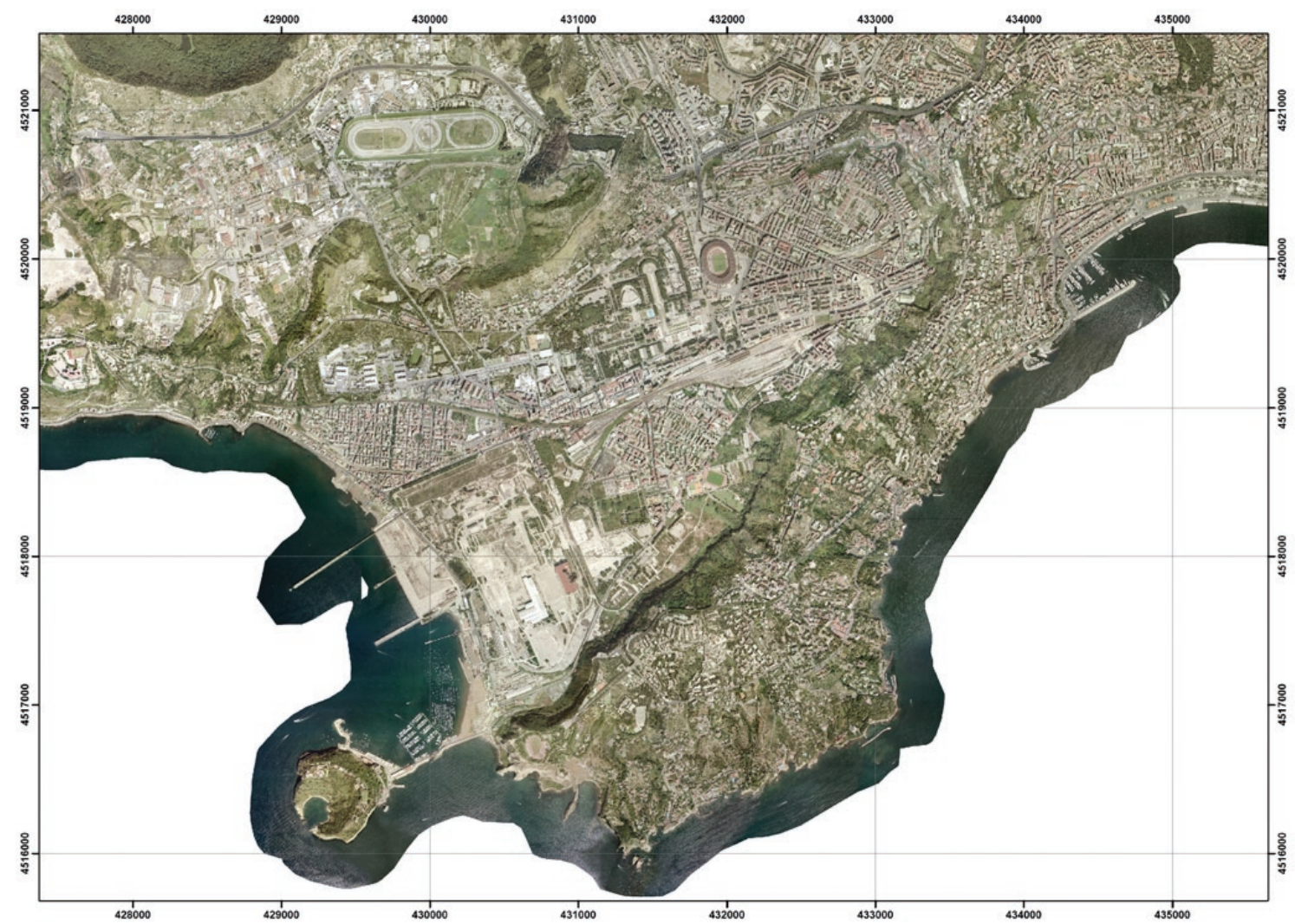

Fig. 22. Ortophoto of the Posillipo hill. Source: Campania Region - Department of Land Use Policies; year: 2004-2005; spatial resolution: $0.2 \mathrm{~m} \times 0.2 \mathrm{~m}$.

consequence of the exponential trend in the building activity in at-risk areas. It has been evidenced (see Fig. 20) that, from the 1950s onward, a great number of edifices have been realised in unsafe zones, irrespective not only of the existing urban plans, but also of the more recent rules introduced by the BAs to downgrade landslide hazard and risk.

Despite the BAs' initiatives, no effective action was undertaken in Italy to ensure a sustainable land management, investing in preventive counter-measures rather than in emergency responses. For example, in Calabria region, one of the most critical regions of Italy as to landslides and floods, the State government spent 484 million euros to repair the effects of a single flood episode that occurred in year 2000, while, from 1989 to 2009, only 321 million euros have been allocated to the same region as "ordinary" funds (Cappadona, 2009).

The planning activity of the BAs gave a clear picture of the areal extent of landslide and flood risk in Italy. In the Campania region, $2253 \mathrm{~km}^{2}$ ( $16.5 \%$ of the regional territory) are classified as R3 or R4 for either landslide $\left(1615 \mathrm{~km}^{2}\right)$ or flood $\left(638 \mathrm{~km}^{2}\right)$ risk (data available from http://www.difesa. suolo.regione.campania.it), thus, meaning conditions potentially leading to serious threat to public safety or to loss of human lives; the resources needed to mitigate the regional risk have been evaluated, in year 2008, at more than 5.5 billion euros (data available from http://www.geologicampania.it).

The amount of financial resources really required is probably higher than above indicated, as it can be demonstrated by a cost-benefit analysis performed on a single case-study. Within the territory managed by BANCR a retention debris basin was realised some years ago to protect against future flow-like movements in Quindici, one of the five towns hit by the May 1998 landslide event (Del Prete et al., 1998; Calcaterra et al., 1999). The efficiency of the basin (net capacity: $57000 \mathrm{~m}^{3}$; overall cost: 9.5 million euros) was jointly analysed by BANCR and Campania Region, through an integrated engineering-geological and hydraulic modelling, which resulted in quantifying the residual risk existing in the urban areas located downvalley with respect to the basin (Calcaterra and Gisonni, 2010): the simulations allowed the verifying of that, thanks to the basin, the landslide and flood risk was downgraded over an area of less than $1 \mathrm{~km}^{2}$.

From the above experience, it should appear evident to anyone that an exclusive "structural way" to reduce landslide and flood risk in Italy, as in any other country of the world, is unattainable. A comprehensive strategy devoted to an effective mitigation of landslide hazard in a territory already devastated by urban speculation, even if formally protected 
by a number of good laws, should be centred upon the concept of "resilience". Resilience is the ability of a system, community or society exposed to hazards to resist, absorb, accommodate to and recover from the effects of a hazard in a timely and efficient manner, including through the preservation and restoration of its essential basic structures and functions (UNISDR, 2009). Chung (2010) has evidenced four key-elements in enhancing community resilience to landslide hazard: proactive public communication and education; comprehensive information services; early warning; effective emergency response. Three of these elements aim at improving the societal preparedness to emergency, an issue which in Italy has been recently dealt with promising success. To this respect, the EDURISK project (www.edurisk.it) can be mentioned, whose aim is to develop educational tools on natural hazards such as earthquakes and volcanic eruptions, through the combined efforts of an interdisciplinary group of experts (geologists, seismologists, engineers, psychologists, pedagogists, editors and publishers). A further good example of non-structural solutions against natural hazards is given by the national emergency plan designed by the Italian authorities to protect the inhabitants from a possible eruption of Mt. Vesuvius (http://www.protezionecivile. gov.it). In addition to the hazard zonation, the plan is also based upon emergency-response and evacuation exercises (e.g., MESIMEX - Major Emergency SIMulation EXcercise - 2006), essential to increase awareness of volcano-related hazards and to minimize future adverse consequences. It is, therefore, hoped that in the near future also landslide hazard will be conveniently tackled through suitable preventive, non-structural measures, bearing in mind that "every dollar spent in preparing for a natural disaster saves seven in response" (World Bank, 2004).

\section{Conclusions}

Because of their geological and geomorphological structure, Naples and the island of Ischia have a long history of geohazards and related disasters, which, as regards to slope instabilities, date back to at least $2000 \mathrm{yr}$ ago. For centuries local populations have built and lived safely far from landslideprone areas, showing a certain awareness of the threat posed by hillslope movements. Also the public authorities seemed in the past much more conscious of what was required to prevent or mitigate the related hazard. In 1817, Giuseppe d'Auletta, an official charged by the Bourbon King Ferdinando I with a statistical analysis of the province of Naples (Di Lorenzo, 2006), wrote “... in the Camaldoli Mountains of Naples copious runoff water concentrate, which, rushing down the ravines, cause damage due to the absence of levees or the lack of drainage". Noteworthy to recall is that the same Bourbon Kings in the 19th century completed the so called Regi Lagni (which can be literally translated as "Royal Channels"), a huge and complex network of channels, which up-to-date drain a territory of several hundreds of square kilometres, from the lower slopes of Mt. Pizzo d'Alvano and Mt. Somma-Vesuvius, through the Volturno River plain, to the Tyrrhenian Sea.

As it results from the present study, the number of people threatened by landslides both in Naples and Ischia is much larger nowadays than in the past, even though specific zoning rules exist from 1999 onward. Following Schuster and Highland (2007), it is, therefore, confirmed, once again that, despite the relevant advances in applying remedial measures against landslides, human pressure existing on a worldwide basis has resulted in a general increase of landslide hazard in urban environments. This occurred not only in Ischia, were population grew up between $32 \%$ and $102 \%$ from 1961 to 2001, but in Naples as well, where, on the contrary, the number of inhabitants has not changed in the last five decades (MGCN, 2007). In fact, in both settings, the number of buildings realised in at-risk areas has significantly increased also in very recent years, during which clear and strict regulations aimed at downgrading the landslide risk have been enacted by BANCR.

These regulations substantially follow the four approaches suggested by Schuster and Highland (2007):

- restricting development in landslide-prone urban areas;

- requiring (by means of codes) that human activities not contribute to slope instability;

- protecting existing developments and population by physical mitigation measures;

- development and installation of monitoring and warning systems.

In this framework, BANCR has given a special role to issues related to agricultural practices. In fact, also in urban areas where natural slopes are significantly present, a diligent landslide risk mitigation strategy should incorporate (Calcaterra et al., 2007):

- a financial support dedicated to restart the land management and agricultural practices, such as the restoration and upkeep of terraces;

- measures aimed at reintroducing a wood cover, especially in the lower reaches of the slopes, to protect the foothill settlements from the downvalley movement of some types of slope instabilities, such as rockfalls;

- effective measures of prevention and mitigation of wildfires.

The above framework must naturally take due account of the disproportion existing between resources needed to protect the territory against geohazards and funds effectively available to this scope. A key-point is, therefore, to find a 
wise balance between structural and non-structural mitigation measures. Among the physical measures, the BANCR rules assign a prominent role to a low environmental impact approach to landslide risk reduction, based upon the soilbioengineering techniques. In the last years, these techniques have already proven successful in mitigating the hazard related to surficial, small-scale slides involving the pyroclastic terrains of the Campania region.

Among the non-structural measures encompassed by the BANCR rules, a variety of options are suggested, such as monitoring and early warning systems, variants to existing building codes, emergency response planning and training, public awareness programmes.

However, in urban environments where the main anthropogenic factor predisposing to adverse consequences is the high number of illegal buildings, the need for "extreme" measures cannot be neglected. This is the case of the insurance coverage against landslides and of urban programs based on the demolition of unauthorised dwellings realised in at-risk areas.

As far as landslide insurance is concerned, it is a long debated issue in Italy, and a number of proposals of law have been presented to Parliament over the last ten years (e.g., the Finance Laws of 2004 and 2005); however, up to now, no decision has been taken. On the contrary, the three cited building amnesties already encompass the possibility for the illegal dwellings to be demolished. Notwithstanding this, during the last months, in the Campania region strong protests were organized by citizens against demolition orders issued by the tribunals. Consequently, the Italian government declared the need to "assess the situation and find a solution".

In conclusion, it should be evident that in Italy it is not a matter of missing or inadequate laws or rules, both at national and local level: the critical point is their respect. Whatever the guideline is to be adopted, it is hoped that, differently from what happened until now, the State will not simply enact further "perfect" laws, but will take the responsibility to obtain from citizens the compliance of the existing rules. This should be the main commitment for the near future, along with ensuring adequate funds and resources for both structural and non-structural measures, so as to guarantee a true land planning and management, especially in those regions, such as Campania, where "parallel" criminal systems have established a strong control over the territory.

Acknowledgements. Architect Francesca Pignataro (Dept. of Urban Planning, City of Naples) and Professor Alfredo Buccaro (Centro Interdipartimentale di Ricerca sull'Iconografia della Città Europea, Federico II University of Naples) are gratefully acknowledged for providing some of the historical maps of Naples. Sincere thanks are due to two anonymous reviewers, who greatly improved an initial version of the manuscript. Research partly funded by the Federico II University of Naples (funds granted to D. Calcaterra).
Edited by: F. Luino

Reviewed by: two anonymous referees

\section{References}

Alessio, M., Bella, F., Improta, S., Belluomini, G., Calderoni, G., Cortesi, C., and Turi, B.: University of Rome C-14 dates XII, Radiocarbon 15, 165-178, 1973.

Almagià, R.: Geographic studies on landslides in Italy, Memorie Società Geografica Italiana, 13, 1-343, 1907 (in Italian).

Almagià, R.: Geographic studies on landslides in Italy, The central and southern Apennines. General conclusions, Memorie Società Geografica Italiana, 14, 1-435, 1910 (in Italian).

Arrigoni, L., Chiesa, S., and Garzonio, A.: Landslide hazard in the island of Ischia (Naples), Geologia Applicata e Idrogeologia, 30(1), 279-295, 1995 (in Italian).

Ascione, A., Cinque, A., Franza, A., and Romano, P.: The geomorphic control on the initiation and propagation of the Mount Di Vezzi landslides (Ischia island, Italy) occurred on 30th April 2006, Italian J. Eng. Geol. Environ., 2, 93-118, 2007.

Barra, D., Cinque, A., Italiano, A., and Scorziello, R.: The marine Upper Pleistocene at Ischia: paleoecology and relationships with the recent tectonic evolution, Studi Geologici Camerti, Special Vol. (1992/1), 231-243, 1992 (in Italian).

Basin Authority of Northwestern Campania Region (BANCR): Hydrogeomorphological Setting Plan, 4 vol., TPS - SELCA, Naples, Italy, 2002 (in Italian).

Basin Authority of Northwestern Campania Region (BANCR): Hydrogeomorphological Setting Plan - Upgrade year 2010, BANCR, Naples, Italy, 2010 (in Italian).

Beneduce, P., D'Elia, G., and Guida, M.: Slope morphodynamics of the Phlegraean area (Campania): mass movements and linear erosion, Memorie Società Geologica Italiana, 41, 949-961, 1988 (in Italian).

Calcaterra, D.: Landslide hazard in the volcanic districts and in the peri-volcanic areas of Campania region, in: Proc. Intern. Conf. "Montagne di Fuoco - Rischi e Risorse in aree vulcaniche - Vesuvio ed Etna", edited by: Calcaterra, D., Morra, V., Naples - Nicolosi (CT), Italy, 27-28 April 2009, 85-108, 2010 (in Italian).

Calcaterra, D. and Gisonni, C.: Geological and hydraulic hazard in fan areas: methodological report, Basin Authority of Northwestern Campania Region, Naples, Italy, 111 pp., available at http://www.difesa.suolo.regione.campania.it/content/view/90/ 38/, 2010 (in Italian).

Calcaterra, D. and Guarino, P. M.: Recent landslides in the urban area of Naples: the middle-eastern sector, in: Proc. Conf. on "Geologia delle Grandi Aree Urbane”, Bologna, Italy, 4-5 November 1997, 257-261, 1999a (in Italian).

Calcaterra, D. and Guarino, P. M.: Morphodynamics and recent landslides in the Neapolitan slopes (western sector), Geologia Tecnica ed Ambientale, 2/99, 11-17, 1999b (in Italian).

Calcaterra, D. and de Luca Tupputi Schinosa, F.: The February 28, $1868 \mathrm{Mt}$. Echia rockfall in the framework of the historical and present-day landslide activity at Naples, Italy, Geophys. Res. Abstr., 8, 04708, EGU General Assembly 2006, Vienna, Austria, 2006.

Calcaterra, D., Parise, M., Palma, B., and Pelella, L.: The May 5th 1998, landsliding event in Campania (southern Italy): inventory of slope movements in the Quindici area, in: Proc. Intern. Symp. 
on “Slope Stability Engineering”, IS - Shikoku '99, Matsuyama, Japan, 1361-1366, 1999.

Calcaterra, D., Parise, M., Palma, B., and Pelella, L.: The influence of meteoric events in triggering shallow landslides in pyroclastic deposits of Campania, Italy, in: Proc. 8th Intern. Symp. on Landslides, Cardiff, UK, 26-30 June 2000, vol. 1, 209-214, 2000.

Calcaterra, D., de Riso, R., Nave, A., and Sgambati, D.: The role of historical information in landslide hazard assessment of urban areas: the case of Naples (Italy), in: Proc. 1st European Conf. on Landslides, Prague, Czech Republic, 24-26 June 2002, 129-135, 2002.

Calcaterra, D., de Riso, R., and Santo, A.: Landslide hazard and risk mapping: experiences from Campania, Italy, in: Proc. Intern. Conf. on Fast Slope Movements: Prediction and Prevention for Risk Mitigation, Naples, Italy, 11-13 May 2003, vol. 1, 63-70, 2003a.

Calcaterra, D., Del Prete, S., and Mele, R.: The influence of landslides on the coastal settlements of the Phlegrean district (Campania region, Italy), in: Proc. Intern. Conf. CITTAM 2003 “The requalification of Mediterranean coasts among tradition, development and sustainability", Naples, Italy, 26-28 June 2003, 524 534, 2003b (in Italian).

Calcaterra, D., de Riso, R., and Di Martire, D.: Assessing shallow debris slide hazard in the Agnano Plain (Naples, Italy) using SINMAP, a physically based slope-stability model, in: Proc. 9th Intern. Symp. on Landslides, Rio de Janeiro, Brazil, 177-183, 2004a.

Calcaterra, D., de Riso, R., Evangelista, A., Nicotera, M. V., Santo, A., and Scotto Di Santolo, A.: Slope instabilities of the pyroclastic deposits in the Phlegraean district and in the carbonate Apennine (Campania, Italy), in: Proc. Intern. Workshop on Occurrence and Mechanisms of Flows in Natural Slopes and Earthfills, Sorrento, Italy, May 14-16, 2003, 61-75, 2004b.

Calcaterra, D., de Riso, R., and Di Martire, D.: Assessment of landslide susceptibility in the Agnano Plain (Naples) by means of a physically-based model (SHALSTAB), in: Proc. Workshop "Modelli matematici per la simulazione di Catastrofi Idrogeologiche", Arcavacata di Rende, Italy, 30-31 March 2004, 355368, 2005 (in Italian).

Calcaterra, D., Coppin, D., De Vita, S., Di Vito, M. A., Orsi, G., Palma, B., and Parise, M.: Slope processes in weathered volcaniclastic deposits within the city of Naples: the Camaldoli Hill case, Geomorphology, 87, 132-157, 2007a.

Calcaterra, D., Parise, M., Strumia, A., and Mazzella, E.: Relations between fire, vegetation and landslides in the heavily populated metropolitan area of Naples, Italy, in: Proc. 1st North American Landslides Conf., Vail, Colorado, June 3-8, 2007, A.E.G. Special Publ. n. 23, 1448-1461, 2007b.

Calcaterra, D., de Luca Tupputi Schinosa, F., Evangelista, A., Ruopolo, S., and Scotto di Santolo, A.: Modeling of rainfallinduced surficial slide-flows in the pyroclastic deposits of the Astroni crater (Phlegrean Fields), in: Proc. 1st Italian Workshop on Landslides "Rainfall-induced landslides: mechanisms, monitoring techniques and nowcasting models for early warning systems", Naples, Italy, 8-10 June 2009, vol. 2, 9-19, 2010a (in Italian).

Calcaterra, D., Di Crescenzo, G., Di Martire, D., Di Natale, M., Gisonni, C., Santillo, A., and Santo A.: Comparison between hyperconcentrated flow runout models: the case-study of Casamic- ciola Terme (Ischia), in: Proc. XXXII Italian Conf. of Hydraulics and Hydraulic Constructions, Palermo, Italy, 14-17 September 2010, 10 pp., 2010 b (in Italian).

Cappadona, P.: Soil defence in Calabria region: planning, programming and realisation of risk reducing measures, in: Proc. Seminar on "Il Passato che ritorna: secoli di catastrofi idrogeologiche e di interventi inadeguati", Arcavacata di Rende, Italy, 25 November 2009, available at: http://www.camilab.unical.it/glimrid/pdf/ cappadona.pdf, 2009 (in Italian).

Chiocci, F. L. and De Alteriis, G.: The Ischia debris avalanche: first clear submarine evidence in the Mediterranean of a volcanic island prehistorical collapse, Terra Nova, 18, 202-209, 2006.

Chiocci, F. L., Martorelli, E., Sposato, A. and T.I.VOL.I Research Group: First TOBI images of the central-southern Tyrrhenian sea-floor (eastern sector), Geologica Romana, 34, 207-222, 1998 (in Italian).

Chung, P. W. K.: Enhance community resilience to landslide hazard, 3rd Intern. Disaster and Risk Conf., IDRC 2010, May 30June 3 2010, Davos, Switzerland, available at: https://www. conftool.com/idrc2010, 2010.

De Alteriis, G. and Violante, C.: Catastrophic landslides off Ischia volcanic island (Italy) during prehistory, in: Geohazard in Rocky Coastal Areas, edited by: Violante, C., The Geological Society, London, Special Publications, 322, 73-104, 2009.

De Lucia, V. E. and Jannello, A.: Urban planning at Naples from the post-war years to-date: notes and documents, Urbanistica, 65, 1-81, 1976 (in Italian)

de Riso, R., Budetta, P., Calcaterra, D., Santo, A., Del Prete, S., De Luca, C., Di Crescenzo, G., Guarino, P. M., Mele, R., Palma, B., and Sgambati, D.: Landslides in the Lattari Mts. and in the Phlegrean area (Campania region): scenarios of landslide susceptibility in test-areas, Quaderni di Geologia Applicata, 11(1), 5-30, 2004 (in Italian).

de Riso, R., Budetta, P., Calcaterra, D., and Santo, A.: Discussion on the behaviour of the unchannelled rapid flows of Campania region, on the basis of previous experiences, in: Proc. Italian Conf. on "La mitigazione del rischio da colate di fango a Sarno e negli altri Comuni colpiti dagli eventi del maggio 1998", Naples, Italy, 2-3 May 2005, 81-92, 2007 (in Italian).

De Seta, C.: The "Casali" of Naples, Giuseppe Laterza e Figli Editore, Rome-Bari, 1984 (in Italian).

De Vita, P., Di Clemente, E., Rolandi, M., and Celico, P.: Engineering geological models of the initial landslides occurred on the April 30th, 2006, at the Mount Di Vezzi (Ischia Island, Italy), Italian J. Eng. Geol. Environ., 2(2007), 119-141, 2007.

Dell'Erba, L.: The Neapolitan Yellow Tuff. Scientific and technical study extended to quarries and landslides, R. Pironti Editore, Naples, Italy, 1923 (in Italian).

Del Prete, S. and Mele, R.: The influence of landslides on coastal morphodynamics of the Island of Ischia, Bollettino Società Geologica Italiana, 118, 339-360, 1999 (in Italian).

Del Prete, S. and Mele, R.: The contribution of historical information to the assessment of instability susceptibility in the Island of Ischia (Campania region), Rendiconti Società Geologica Italiana, 2(2006), new series, 29-47, 2006 (in Italian).

Del Prete, M., Guadagno, F. M., and Hawkins, A. B.: Preliminary report on the landslides of 5 May 1998, Campania, southern Italy, Bull. Eng. Geol. Env., 57, 113-129, 1998.

Di Lorenzo, A.: The north-western hills of Naples: historical evo- 
lution of an urban landscape, $\mathrm{PhD}$ Thesis, Federico II University of Naples, Italy, 290 pp., 2006 (in Italian).

Di Vito, M. A., Isaia, R., Orsi, G., Southon, J., De Vita, S., D'Antonio, M., Pappalardo, L., and Piochi, M.: Volcanism and deformation since 12.000 years at the Campi Flegrei caldera (Italy), J. Volcanol. Geotherm. Res., 91, 221-246, 1999.

Fiorillo, A., Laurenti, M., Merola, M., Mani, P., and Bianchi D. (Eds.): 2007 Urban ecosystem, Legambiente, 62 pp., available at: http://www.legambiente.it/contenuti/dossier/ ecosistema-urbano-2007, 2007 (in Italian).

Guadagno, F. M. and Mele, R.: The fragile Island of Ischia, Geologia Applicata e Idrogeologia, 30, 177-187, 1995 (in Italian).

Hartlèn, J. and Viberg, L.: General report: evaluation of landslide hazard, in: Proc. 5th Int. Symp. on Landslides, Lausanne, Switzerland, 10-15 July 1988, 2, 1037-1057, 1988.

Heim, A.: Landslides and human lives (Bergstürz and Menchen leben), Translated by: Skermer, N., BiTech Publishers, Canada, 1932.

Iovino, M. and Perriello Zampelli, S.: The April 30th, 2006 Mount Vezzi landslides (Ischia island, Italy) in the context of the sliding susceptibility of volcanic soils in Campania, Italian J. Eng. Geol. Environ., 2, 73-91, 2007.

Luongo, G., Carlino, S., Cubellis, E., and Obrizzo, F.: Ischia Island (Southern Italy): a model of caldera resurgence. Rendiconti online Società Geologica Italiana, 3, 499-500, 2008.

Mazzoleni, S., Amato, M., Di Gennaro, A., Cembalo, F., Lanzotti, V., Di Pasquale, G., Di Martino, P., Giordani, D. M., Abalsamo, P., Cona, F., Bellelli, M., Strumia, S., Migliozzi, A., and Vitelli, L.: Analysis of the Neapolitan soil-vegetation system in relation to slope instability dynamics and definition of intervention guidelines, C.U.G.Ri., Naples-Salerno, Italy, unpublished report, 94 pp., 2001 (in Italian).

Mele, R. and Del Prete, S.: Mass movements in the Green Tuff on Mt. Epomeo (Ischia Island - Campania region), Bollettino Società Geologica Italiana, 117, 93-112, 1998 (in Italian).

Monti, S.: Thermalism between past and future, in: Proc. Conf. on "The cultural turn in geography", Gorizia, Italy, 18-20 September 2003, International Geographical Union, 305-312, 2006.

Morra, V., Calcaterra, D., Cappelletti, P., Colella, A., Fedele, L., de' Gennaro, R., Langella, A., Mercurio, M., and de' Gennaro, M.: Urban geology: relationships between geological setting and architectural heritage of the Neapolitan area, in: The Geology of Italy, edited by: Beltrando, M., Peccerillo, A., Mattei, M., Conticelli, S. and Doglioni, C., J. Virtual Explorer, 36, paper 26, doi:10.3809/jvirtex.2010.00261, 2010.

Municipal Government of the City of Naples - MGCN: The population of Naples from 1951 to 2001, SISTAN, Servizio Statistico Nazionale, 121 pp., 2007 (in Italian).

Orsi, G., Gallo, G., and Zanchi, A.: Simple shearing block resurgence in caldera depressions. A model from Pantelleria and Ischia, J. Volcanol. Geotherm. Res., 47, 1-11, 1991.
Orsi, G., D’Antonio, M., de Vita, S., and Gallo, G.: The Neapolitan Yellow Tuff, a large-magnitude trachytic phreatoplinian eruption: eruptive dynamics, magma withdrawal and caldera collapse, J. Volcanol. Geotherm. Res., 53, 275-287, 1992.

Orsi, G., De Vita, S., and Di Vito, M. A.: The restless, resurgent Campi Flegrei nested caldera (Italy): constraints on its evolution and configuration, J. Volcanol. Geotherm. Res., 74, 179214, 1996.

Palma, B., Calcaterra, D., and Parise, M.: Geological models and triggering mechanisms of slide-flows in the volcaniclastic deposits of Campania region (Italy), Geoingegneria Ambientale e Mineraria, 46, 21-48, 2009 (in Italian).

Parise, M., Calcaterra, D., de Luca Tupputi Schinosa, F., and Palma, B.: Rockfall stability assessment at the western slope of Camaldoli Hill (Naples, Italy), in: Proc. 9th Intern. Symp. on Landslides, Rio de Janeiro, 28 June-7 July 2004, 257-263, 2004.

Pellegrino, A.: Landslides in the Province of Naples, in: Proc. Symp. on Natural hazards and human impact in the Province of Naples, Naples, Italy, 7-8 June 1991, Acta Neapolitana, 18, 237-256, 1994 (in Italian).

Rittmann, A. and Gottini, V.: The Island of Ischia. Geology, Bollettino Servizio Geologico Italiano, 101, 131-274, 1980 (in Italian).

Scaramella, M.: The case of Naples, Italy, in Understanding slums: Case Studies for the Global Report 2003, United Nations Human Settlements Programme, 21 pp., available at: http://www.ucl.ac. uk/dpu-projects/Global_Report/home.htm, 2003.

Schuster, R. L. and Highland, L. M.: The Third Hans Cloos Lecture. Urban landslides: socioeconomic impacts and overview of mitigative strategies, Bull. Eng. Geol. Environ., 66, 1-27, 2007.

Sorriso Valvo, M.: Landslide risk assessment in Italy, in: Landslide Hazard and Risk, edited by: Glade, T., Anderson, M., and Crozier, M. J., John Wiley and Sons, Chichester, UK, 699-732, 2005.

Tinti, S., Pagnoni, G., Zaniboni, F., and Bortolucci, E.: Tsunami generation in Stromboli island and impact on the south-east Tyrrhenian coasts, Nat. Hazards Earth Syst. Sci., 3, 299-309, doi:10.5194/nhess-3-299-2003, 2003.

Touring Club Italiano - TCI: Naples and its surroundings, TCI, Milan, Italy, 797 pp., 2001 (in Italian).

United Nations Human Settlements Programme - UnHabitat: The challenge of slums. Global report on human settlements 2003, Earthscan Publications Ltd, London, UK, 345 pp., available at: http://www.unhabitat.org/pmss/, 2003.

United Nations International Strategy for Disaster Reduction (UNISDR): UNISDR Terminology on Disaster Risk Reduction. UNISDR, Geneva, 35 pp., available at http://www.unisdr.org/ we/, 2009.

Vezzoli, V.: Island of Ischia, C.N.R., Quaderni de "La Ricerca Scientifica", 114, 1-133, Rome, 1988.

World Bank: Natural Disasters: counting the cost. Washington, DC, 2004. 